(C) 2019. This manuscript version is made available under the CCBY-NC-ND 4.o license http://creativecommons.org/licenses/by-nc-nd/4.o/ 


\section{ScienceDirect}

$: \equiv \quad \&$ Get Access Share Export

\section{Spectrochimica Acta Part A: Molecular and \\ Biomolecular Spectroscopy}

Volume 211, 15 March 2019, Pages 383-392

\section{The conformation of chloramphenicol in the ordered and disordered phases}

Emilio Meaurio ${ }^{a} \stackrel{\circ}{\otimes}$, Eva Sanchez-Rexach ${ }^{a}$, Amaia Butron $^{b}$, Jose-Ramon Sarasua ${ }^{a}$

a Department of Mining-Metallurgy Engineering and Materials Science, POLYMAT, University of The Basque Country (UPV/EHU), School of Engineering, Alameda Urquijo s/n, Bilbao, Spain

b Tecnalia, Sede Azpeitia, Área Anardi 5, E-20730 Azpeitia, Gipuzkoa, Spain

Received 4 July 2018, Revised 5 December 2018, Accepted 9 December 2018, Available online 10 December 2018.

D) Check for updates

$\boxminus$ Show less

\section{Highlights}

- The cooperative $\mathrm{O}-\mathrm{H} \cdots \mathrm{O}-\mathrm{H}$ interactions in crystalline $\mathrm{CHL}$ reveal its actual conformation.

- Melting involves the reversal of the intramolecular hydrogen bonds.

- In vacuum, the major conformers of $\mathrm{CHL}$ present an hydrogen and an halogen bond.

- In polar solvents a second conformer of higher polarity is stabilized to get similar importance. 


\title{
The Conformation of Chloramphenicol in the ordered and disordered phases.
}

\author{
Emilio Meaurio $^{1 *}$, Eva Sanchez-Rexach ${ }^{1}$, Amaia Butron ${ }^{2}$, Jose-Ramon Sarasua $^{1}$ \\ ${ }^{1}$ Department of Mining-Metallurgy Engineering and Materials Science, POLYMAT, \\ University of The Basque Country (UPV/EHU), School of Engineering, Alameda \\ Urquijo s/n, Bilbao, Spain.
}

${ }^{2}$ Tecnalia, Sede Azpeitia, Área Anardi 5, E-20730 Azpeitia - Gipuzkoa (Spain)

* Corresponding author. Fax: +34-94-601-3930

Email: emiliano.meaurio@ehu.eus (E. Meaurio) 


\begin{abstract}
The conformational behavior of chloramphenicol (CHL) in the solid, liquid and vapor phases is revisited here by means of FTIR spectroscopy and QM methods. In the crystalline phase, both the IR analysis and QM computations discard the conformer proposed by Acharya et al. (Acta Cryst., 1979, B35:1360-1363) and support the one proposed by Chatterjee et al. (J. Cryst. Mol. Struct., 1979, 9:295-304), characterised by an intramolecular $\mathrm{O}-\mathrm{H} \bullet \bullet \mathrm{O}$ hydrogen bond in which the primary hydroxyl group acts as hydrogen bond donor. The conformational behavior of CHL in the liquid and gas phases has been analyzed using QM calculations. The Self-Consistent Reaction Field (SCRF) method with the Onsager solvation model has been used for the initial optimizations in solution, and the lowest energy conformers have been refined using the Solvation Model based on Density (SMD). In solution environment the intramolecular $\mathrm{O}-\mathrm{H} \bullet \bullet \mathrm{O}$ hydrogen bond in CHL is reversed so that the secondary hydroxyl group acts as hydrogen bond donor. In addition, the dichloroacetamide group folds back further over the phenyl ring to form an intramolecular $\mathrm{C}-\mathrm{Cl} \bullet \bullet \pi$ halogen bond. Two different halogen bonds are actually observed (each one with a different chlorine atom) resulting in two different stable conformers, that can be detected by FTIR spectroscopy due to the conformational sensitivity of the $\mathrm{C}=\mathrm{O}$ group to the conformation of the dichloroacetyl group. Finally, the stability of the conformers with the polarity of the medium is also discussed.
\end{abstract}

Keywords: Chloramphenicol (CHL); conformation; interactions; hydrogen bonding; halogen bonding. 


\section{Introduction}

Chloramphenicol (CHL) is a broad-spectrum antibiotic isolated originally from Streptomyces venezuelae in 1947 [1, 2]. Its structure was soon elucidated, and it became the first antibiotic to be synthesized by chemical means $[1,2]$. CHL acts essentially as a bacteriostatic agent, inhibiting bacterial synthesis by binding to the $50 \mathrm{~S}$ subunit of $70 \mathrm{~S}$ ribosomes [1, 3]. It can be used to treat a wide range of microorganisms [1, 2, 3, 4], and is currently included in List of Essential Medicines (EML) published by the World Health Organization (WHO) [5].

CHL contains different reactive groups that have been exploited to obtain derivatives (more than 500 compounds have been reported) and to explore structureactivity relationships $[1,2]$. The molecule of CHL (scheme 1) can be divided in three parts: (I) a p-nitrobenzene moiety, (II) a dichloroacetyl moiety and (III) a 2-aminopropanediol moiety [1, 2]. The aromatic part (I) and the acyl side chain (II) can be modified without suppressing in vitro protein synthesis inhibition [2] and are thus less critical for antibacterial activity [1, 2]. On the other hand, the propanediol moiety (III) contains two asymmetric Carbons, and among the four possible stereoisomers, only the D-threo configuration (the one occurring on CHL) presents high antibacterial activity. This stereospecificity suggests that the conformation plays a crucial role on antibacterial activity.

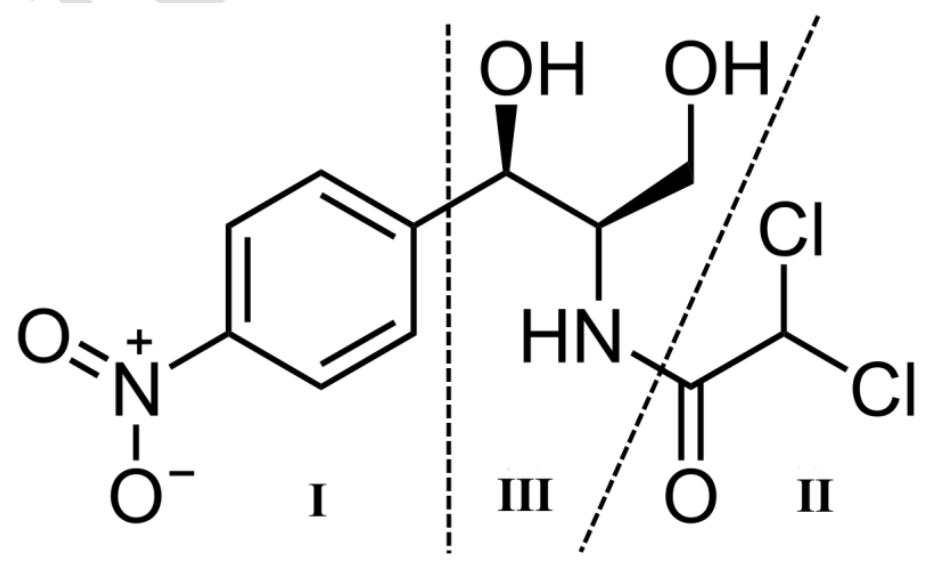

Scheme 1. Chemical structure of CHL.

The conformational analysis of CHL is therefore of great interest both from the fundamental and applied points of view. By means of NMR spectroscopy, it has been 
shown that the geometry of the free CHL molecules in solution does not change upon binding to the Escherichia coli 70S ribosome [6]. Since flexible ligands usually undergo substantial deformations upon binding to receptors [7], CHL behaves like a stiff molecule. One of the goals of the works trying to stablish the molecular mechanism responsible for the antibacterial activity is the comparison of the geometry of the ligand in the binding site with its free geometry in solution or with its geometry in the crystals [8].

Unfortunately, there is currently no consensus on the actual conformation of pure CHL, since a number of contradictory results have been published $[9,10,11,12,13,14$, 15, 16]. The conformation of crystalline CHL was investigated by Chatterjee [10] and Acharya [11] in 1979. However, both authors proposed different geometries differing in the arrangement of the intramolecular hydrogen bond. According to Chatterjee, the primary hydroxyl group acts as hydrogen bond donor and the secondary one as acceptor, but according to Acharya the opposite holds. Both structures are considered in the current literature $[17,18,19,20,21,22]$. Dilute solution studies of free CHL molecules also show conflicting results. Using NMR spectroscopy, Jardetzky [12] concluded the presence of a unique CHL conformer in solvents of different polarity ranging from acetone to water. The predominant conformer contained an intramolecular $\mathrm{O}-\mathrm{H} \cdots \mathrm{O}$ hydrogen bond in which the secondary hydroxyl acts as hydrogen bond donor. However, using NMR spectroscopy and molecular modeling calculations Bustard [14] and Höltje [15] concluded the existence of a second conformer devoid of intramolecular hydrogen bonding. Hahn claimed a definitive study in view of these contradictory reports [1]. To our knowledge, no conformational analysis has been reported using modern QM methods.

This paper revisits the conformation of crystalline CHL and of free CHL molecules in dilute solution using FTIR spectroscopy and QM computations. Solvation effects on conformation have been preliminarily analyzed using the Onsager SCRF solvation model $[23,24]$ and the dominant conformers have been refined using the SMD SCRF solvation model [25]. These implicit models do not require the extensive sampling of explicit methods and trade detail and some accuracy for computational cost $[26,27]$. The conformational behavior in vacuum is also analyzed using QM calculations and the proper intramolecular hydrogen bonding configuration is established in different environments. Finally, the stability of the conformers with the polarity of the medium is also discussed. 


\section{Experimental Section}

\subsection{Starting Materials}

Chloramphenicol (purity $\geq 98 \%$ ) and acetonitrile were supplied by Aldrich Chemical Corp. (Spain) and were used as received.

\subsection{Differential Scanning Calorimetry (DSC)}

Thermal analyses were conducted on a Modulated DSC Q200 from TA Instruments. All the scans were carried out in hermetic aluminum pans under nitrogen atmosphere with sample weights between 5 and $10 \mathrm{mg}$. Two consecutive scans were performed from $-80^{\circ} \mathrm{C}$ to $180^{\circ} \mathrm{C}$ with a scan rate of $20^{\circ} \mathrm{C} / \mathrm{min}$.

\subsection{Fourier Transform Infrared Spectroscopy (FTIR)}

FTIR spectra were recorded on a Nicolet AVATAR 370 Fourier transform infrared spectrophotometer. Spectra were taken with a resolution of $2 \mathrm{~cm}^{-1}$ and were averaged over 64 scans in the $4000-450 \mathrm{~cm}^{-1}$ range. Pure CHL FTIR samples were prepared by grinding $\mathrm{CHL}$ with $\mathrm{KBr}$ and pressing. The absorbance of the samples was within the range where the Lambert-Beer law is obeyed. A controlled high temperature transmission cell mounted in the spectrometer was used to obtain the spectra of molten samples. Second derivative spectra were smoothed using the Norris-Williams Gap Derivatives [28] using maximum gap sizes and segment lengths of 5 points and $5 \mathrm{~cm}^{-1}$ respectively in the derivative transformations.

Spectra in solution was recorded from $1 \mathrm{wt} \%$ CHL solutions in acetonitrile using a variable path length cell equipped with IR grade Silicon windows ( $2 \mathrm{~mm}$ thick). To reduce interference fringes, the background was collected with the cell introduced in the FTIR bench. The spectrum of the solvent was then recorded. Finally, the spectrum of CHL in solution was obtained by subtraction of the solvent spectrum in the appropriate spectral region.

\subsection{Computational Methods.}

The crystallographic information files corresponding to the models of Acharya [11] and Chatterjee [10] (CCDC reference numbers 1127220 and 1127221 respectively) 
were downloaded from the Cambridge Structural Database (CSD) to build the molecular models for the crystals.

The QM analyses of the crystalline structures have been carried out using CrystalExplorer v17.5 [29]. The method used by the program to obtain the lattice energy expresses the energy of interaction between molecules in terms of four key components (Eq. 1): electrostatic, polarization, dispersion, and exchange-repulsion:

$$
E_{\text {tot }}=k_{\text {ele }} E_{\text {ele }}+k_{\text {pol }} E_{\text {pol }}+k_{\text {dis }} E_{\text {dis }}+k_{\text {rep }} E_{\text {rep }}
$$

The program builds molecular clusters to obtain the interaction energy terms (eq. 1) between molecular pairs at the selected level of theory $[30,31,32]$. This methodology was fitted against standard benchmark data sets for intermolecular interactions, and the best performing model was the counterpoise-corrected B3LYP-D2/6-31G(d,p) level [30]. The fitting process involved modifying the scale factors in Eq. 1 to obtain the lowest mean average deviation (MAD) between the model energies and those in the training set. The new methods were termed using the CE (CrystalExplorer) prefix, and the MAD obtained for the CE-B3LYP method was just over $1 \mathrm{~kJ} \mathrm{~mol}^{-1}$ [30].

The conformational search in vacuum has been performed using the Firefly QC package [33], which is partially based on the GAMESS (US) [34] source code. Geometry optimizations were carried out using the hybrid DFT method B3LYP-D3/DZP, consisting on the B3LYP functional $[35,36]$ extended with the D3 version of Grimme's dispersion correction [37]. The DZP basis function is based on the DZ basis function of Dunning [38] plus one set of polarization functions with the exponents recommended by Dunning for correlated calculations: $\mathrm{H}(\mathrm{p})$ 0.935; $\mathrm{C}(\mathrm{d})$ 0.550; $\mathrm{N}(\mathrm{d})$ 0.817; $\mathrm{O}(\mathrm{d}) 1.185 ; \mathrm{Cl}(\mathrm{d}) 0.600$ $[39,40]$. The lowest energy conformers were reoptimized at the B3LYP-D3/def2-TZVP(f) (-f means without f polarization functions) [41], followed by vibrational mode analyses to confirm equilibrium structures. The prevalent structures were also optimized at the MP2/def2-TZVPP level of theory.

A preliminary conformational search in acetonitrile solution was carried out at the B3LYP-D3/DZP/Onsager level of theory, where the Onsager SCRF is used to account for solvation effects $[42,23,43,44]$. This model locates the dipole moment of the solute 
in the center of a spherical cavity, and calculates the interaction energy between the dipole moment and the surrounding solvent, characterized by its dielectric constant. The cavity radius can be determined from the molar volume assuming a nearly spherical solute [44], and was set to $\mathrm{R}=4.4 \AA$ according to the density of amorphous CHL, $1.47 \mathrm{~g} / \mathrm{cm}^{3}$ [45]. Equilibrium geometries were confirmed from vibrational analyses at the same level of theory. The most stable geometries were reoptimized using the ORCA computational package v.4.0.1 [46] at the B3LYP/6-31G(d)/SMD and at the B3LYP-D3/6$311 \mathrm{G}(2 \mathrm{~d}, \mathrm{p}) / \mathrm{SMD}$ levels of theory, where SMD stands for the Solvation Model based on solute electron Density [25]. Further details on the computations can be viewed in the supplementary information.

\section{Results and Discussion}

\subsection{DSC Analysis}

Figure 1 shows the first and second DSC traces obtained for pure CHL. As can be seen, $\mathrm{CHL}$ is a crystalline solid melting at about $151^{\circ} \mathrm{C}$. Cooling in the DSC at about $-20^{\circ} \mathrm{C} / \mathrm{min}$ results in a supercooled liquid with a glass transition temperature located at about $32{ }^{\circ} \mathrm{C}$. Considering this thermal behavior, supercooled CHL at room temperature is in the glassy state and is expected to crystallize very slowly. 


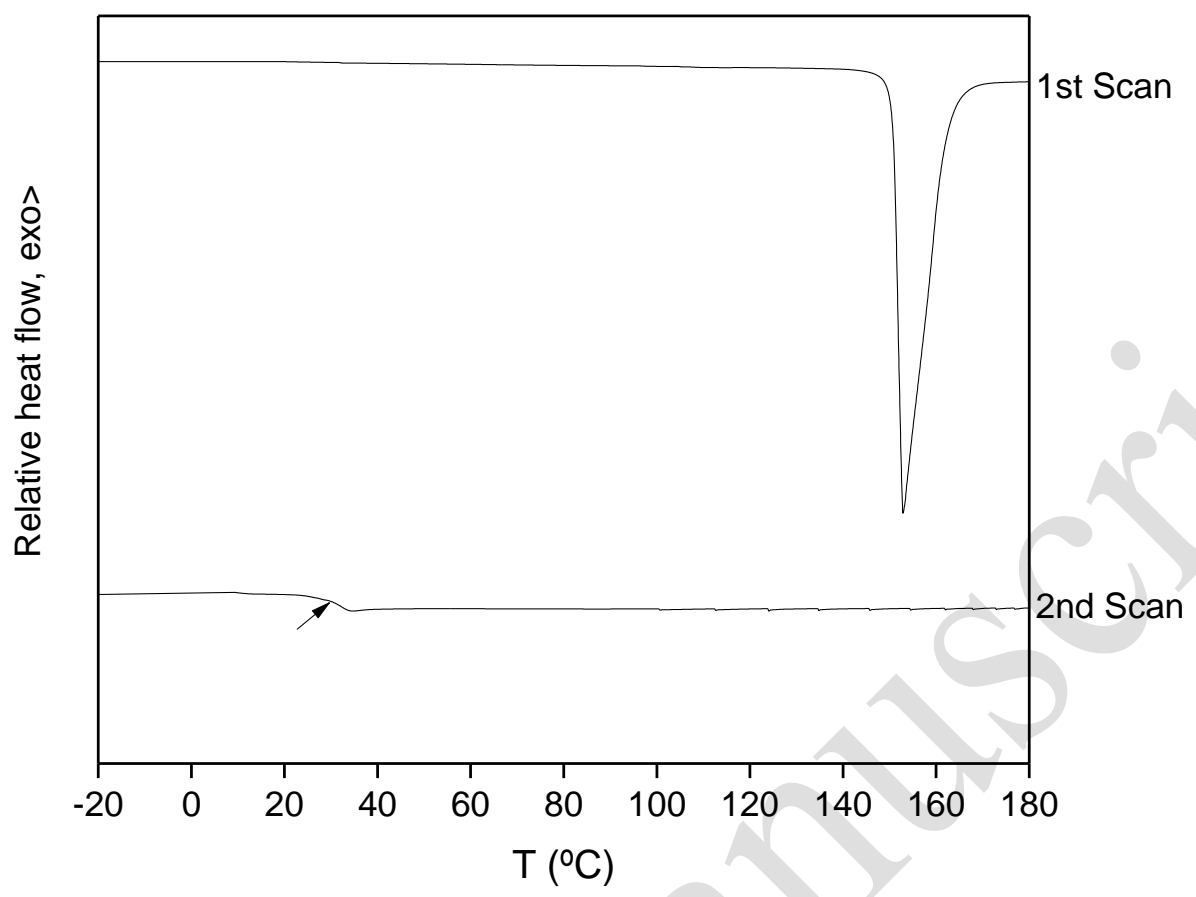

Figure 1. DSC traces for the first and second scans of CHL.

\subsection{FTIR analysis of crystalline CHL.}

The hydrogen bonding pattern and consequently the infrared spectrum of crystalline CHL depend on the molecular conformation and on the crystalline packing. The crystalline structure of CHL was first investigated by Dunitz [9], but the atomic coordinates were reported only later by Chatterjee [10] and Acharya [11]. According to Chatterjee, CHL crystallizes in the orthorhombic space group $\mathrm{C} 222_{1}$, with $\mathrm{a}=17.495 \AA$, $\mathrm{b}=7.321 \AA, \mathrm{c}=$ $22.130 \AA$, and $Z=8[10]$, adopting a conformation in which the dichloroacetamide moiety is folded back over the phenyl ring. Following the usual practice, both authors [10, 11] determined the location of the heavy atoms by means of the X-Ray diffraction data, but the location of the hydrogen atoms was guessed from the molecular structure. However, since the location of the hydroxyl hydrogens is particularly difficult to assess, they proposed different orientations for the $\mathrm{OH}$ groups, resulting in two different conformers with different association patterns in the crystalline structure (Fig. 2). Both conformers present an intramolecular $\mathrm{O}-\mathrm{H} \cdots \mathrm{O}-\mathrm{H}$ hydrogen bond, but in the conformer proposed by Chatterjee the primary hydroxyl acts as donor (Fig. 2a) [10] while in the conformer proposed by Acharya the primary hydroxyl acts as acceptor (Fig. 2b) [11]. Regarding the intermolecular association in the crystalline structure, both models present an 
intermolecular $-\mathrm{N}-\mathrm{H} \cdots \mathrm{O}-\mathrm{H}$ hydrogen bond (to primary $\mathrm{OH}$, Fig. $2 \mathrm{c}$ and $2 \mathrm{~d}$ ) $[10,11]$. However, the model of Chatterjee presents an intermolecular $-\mathrm{O}-\mathrm{H} \cdots \mathrm{O}=\mathrm{C}$ hydrogen bond in which the secondary $\mathrm{OH}$ acts as donor (Fig. 2c) [10] while the model of Acharya presents an intermolecular $-\mathrm{O}-\mathrm{H} \cdots \mathrm{Cl}$ hydrogen bond in which the primary $\mathrm{OH}$ acts as donor (Fig. 2d) [11]. Both structures have received similar attention in the literature, and none has been discarded yet $[17,18,19,20,21,22]$.
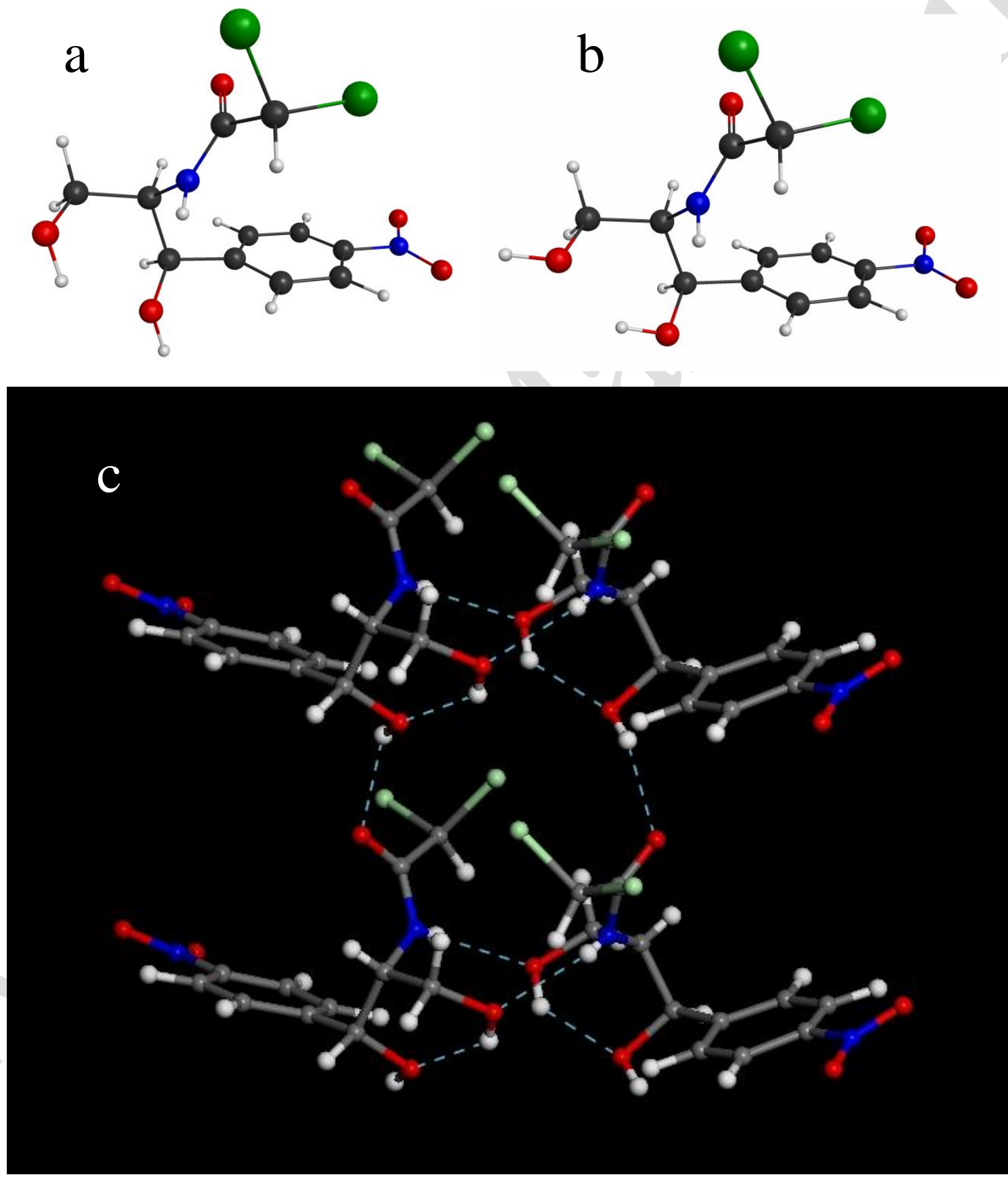


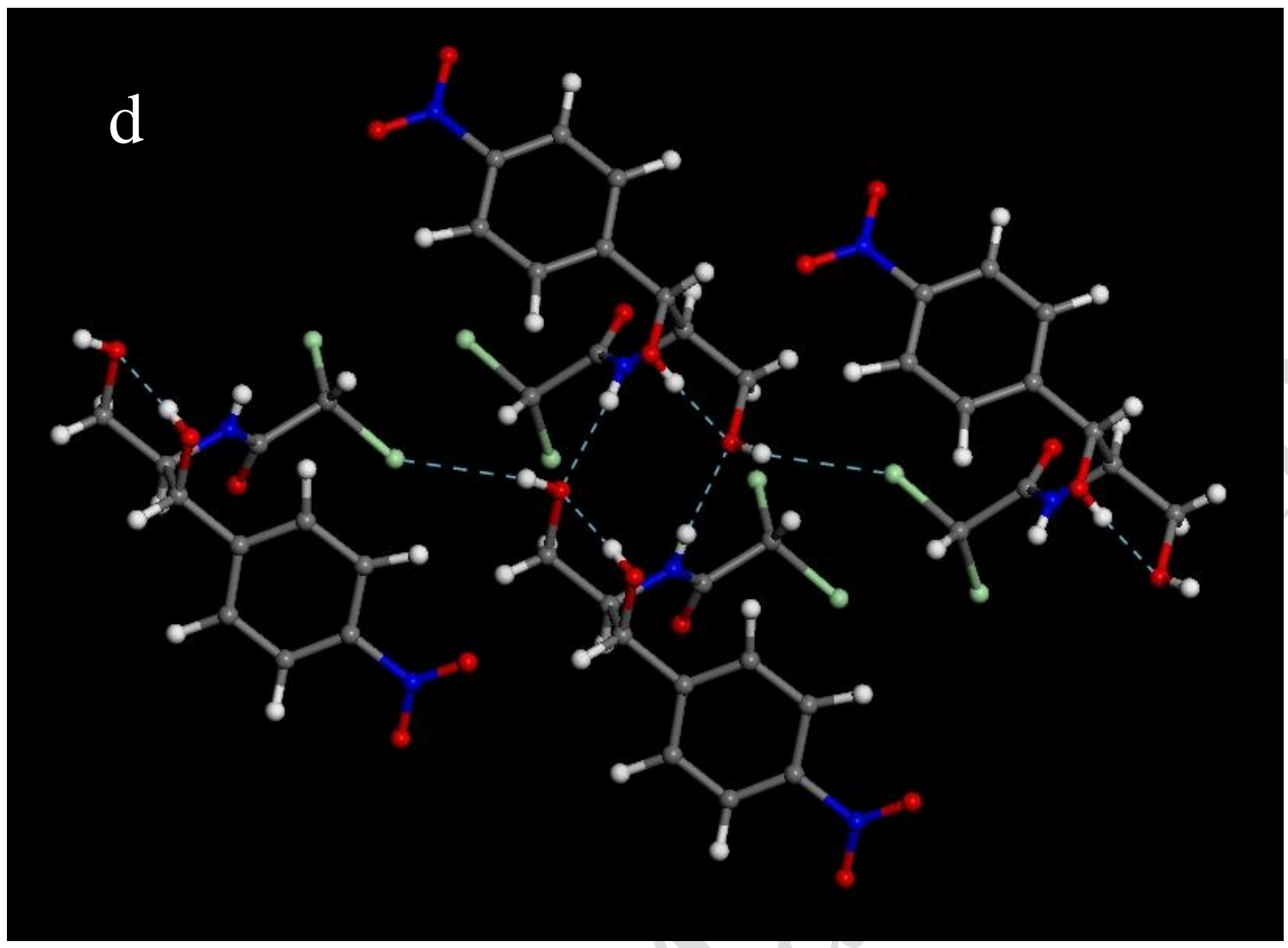

Figure 2. Crystalline conformers proposed by a) Chatterjee [10] and b) Acharya [11] and corresponding hydrogen bonding patterns in the resulting crystalline structures, c) Chatterjee [10] and d) Acharya [11].

Figure 3 shows the $\mathrm{X}-\mathrm{H}$ stretching region for pure crystalline $\mathrm{CHL}$ at room temperature, which can be used to discriminate the correct crystalline structure. As can be seen, pure crystalline CHL shows three bands located at about 3480,3350 and $3260 \mathrm{~cm}^{-1}$. In the solid or liquid phases, hydrogen bonded secondary amides generally exhibit a strong band at about $3270 \mathrm{~cm}^{-1}$ and a weak band at about $3100 \mathrm{~cm}^{-1}$ for the overtone of the Amide II band [47]. Hence, the band at $3260 \mathrm{~cm}^{-1}$ can be attributed to $\mathrm{N}-\mathrm{H}$ stretching. This assignment is supported by the Raman spectrum of CHL in the $\mathrm{X}-\mathrm{H}$ stretching region, where only a single band at about $3260 \mathrm{~cm}^{-1}$ [17] has been reported (the $\mathrm{OH}$ groups are poor scatterers [48] and only display weak, broad Raman bands). According to second derivative spectroscopy, this band is actually split on two components located at about 3260 and $3240 \mathrm{~cm}^{-1}$, a phenomenon typically attributable to Fermi resonance $[49,50](\mathrm{a}$ reasonable candidate is the combination band $1690 \mathrm{~cm}^{-1}+1560 \mathrm{~cm}^{-1} ; \mathrm{C}=\mathrm{O}$ stretch combined with $\mathrm{N}-\mathrm{H}$ in plane bend + ring stretch [17]). Upon melting, the N-H stretching band shifts to higher wavenumbers $\left(\sim 3400 \mathrm{~cm}^{-1}\right)$, indicating the rupture of the $\mathrm{N}-\mathrm{H} \cdots \mathrm{O}-$ 
$\mathrm{H}$ interactions occurring in the crystalline phase, but remains below the typical range for free N-H groups (3460-3440 $\mathrm{cm}^{-1}$ [47]), suggesting the occurrence of weak interactions in the amorphous phase, such as contacts with the aromatic rings.

Hence, the bands located at 3480 and $3350 \mathrm{~cm}^{-1}$ can be attributed to the two $\mathrm{OH}$ groups present in CHL. The band at $3350 \mathrm{~cm}^{-1}$ is strongly red shifted (free $\mathrm{OH}$ stretching occurs in the $3650-3600 \mathrm{~cm}^{-1}$ range [47]) and is only attributable to hydroxyl stretching in cooperatively hydrogen bonded $\mathrm{O}-\mathrm{H} \cdots \mathrm{O}-\mathrm{H}$ systems. The band at $3480 \mathrm{~cm}^{-1}$ can be attributed to the $\mathrm{O}-\mathrm{H} \cdots \mathrm{O}=\mathrm{C}$ interactions (usually in the range $3600-3450 \mathrm{~cm}^{-1}$ [47]) assumed in the model of Chatterjee [10], but is too red shifted to be attributable to the weak $\mathrm{O}-\mathrm{H} \cdots \mathrm{Cl}$ interactions proposed by Acharya [11].

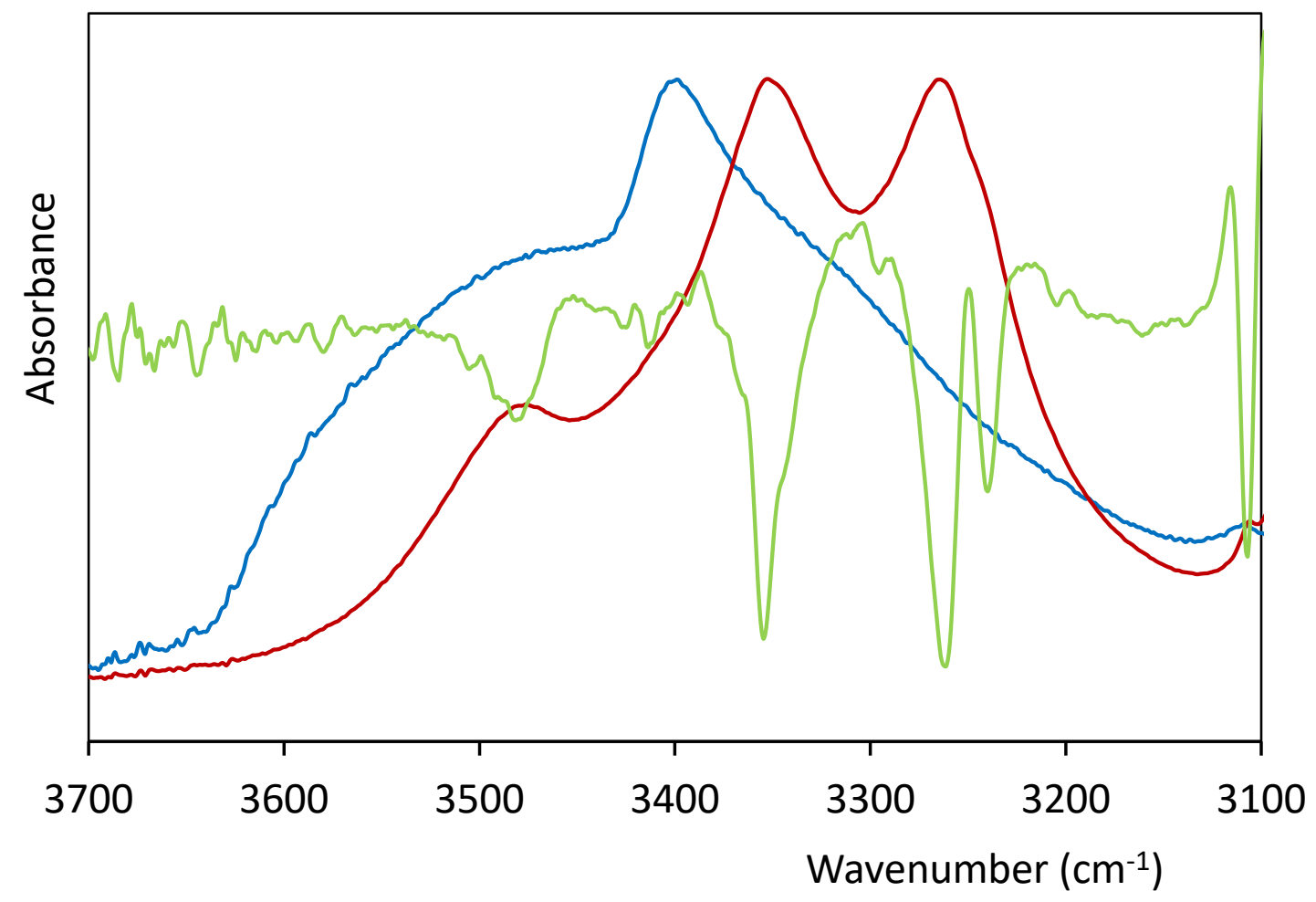

Figure 3. Hydroxyl stretching region for molten $\mathrm{CHL}$ at $160^{\circ} \mathrm{C}$ (blue) and for crystalline $\mathrm{CHL}$ at room temperature (red), along with the second derivative of the latter (green).

The analysis of the hydrogen bonding cooperativity in the models of Chatterjee and Acharya gives additional support to the structure proposed by the former author. In the model of Chatterjee [10], the interacting groups form linear $\mathrm{N}-\mathrm{H} \cdots \mathrm{O}-\mathrm{H} \cdots \mathrm{O}-\mathrm{H} \cdots \mathrm{O}=\mathrm{C}$ chains (see Fig. 2c). However, in the model of Acharya [11] the interacting groups form 
bifurcated $(\mathrm{N}-\mathrm{H})(\mathrm{O}-\mathrm{H})>\mathrm{O}-\mathrm{H} \cdots \mathrm{Cl}-\mathrm{C}$ structures (see Fig. 2d). Recently, Ohno et al. have proposed a simple method to analyze the degree of cooperativity (or the strength of hydrogen bonding) in O-H $\cdots \mathrm{O}-\mathrm{H}$ hydrogen bonded chains [51]. Each $\mathrm{O}-\mathrm{H} \cdots \mathrm{O}-\mathrm{H}$ couple is considered a Donor-Acceptor (DA) group, and the interactions established by D or A with surrounding molecules are assumed to strengthen or weaken the hydrogen bonding interaction between $\mathrm{D}$ and $\mathrm{A}$. The number of protons accepted by $\mathrm{D}$ is termed $a_{D}$ (in the $0-2$ range), the number of protons accepted by $\mathrm{A}$ is $a_{A}(0-1)$, and the number of protons donated by $\mathrm{A}$ is $d_{A}(0-1)$. The hydrogen bonding structure adopted by the DA couple with its surroundings is then characterized by the $a_{D} D A d_{A} a_{A}$ string, and the strength of the DA hydrogen bond is classified according to the cooperativity indicator $M_{O H}=a_{D}+d_{A}-a_{A}$, proportional to the hydrogen bonding energy [51]. Application of this procedure to the $\mathrm{O}-\mathrm{H} \cdots \mathrm{O}-\mathrm{H}$ interaction in the crystalline structure proposed by Chatterjee results in the $1 \mathrm{DA} 10$ string and $\mathrm{M}_{\mathrm{OH}}=2$, but in the Acharya case the string is 0DA11 and the indicator is $\mathrm{MoH}_{\mathrm{OH}}=0$. This analysis indicates strong cooperativity in the structure of Chatterjee, but no cooperativity in the structure of Acharya. For the Structure of Acharya, the intramolecularly hydrogen bonded $\mathrm{OH}$ stretching mode should be located above $3500 \mathrm{~cm}^{-}$ 1 , as in other non-cooperative intramolecularly hydrogen bonded 1,3 diols [52, 53]. For the structure of Chatterjee, cooperativity should be similar to that occurring in tetrols [54, 55], in which the cooperativity indicator is also $\mathrm{M}_{\mathrm{OH}}=2$. These compounds contain four $\mathrm{OH}$ groups arranged linearly in 1,3 relative positions, and have been investigated as model systems for the vibrational spectroscopy of naturally occurring hydrogen bonding networks. In the liquid phase the all-syn tetrol shows a very broad OH-stretching band peaking at $3388 \mathrm{~cm}^{-1}$ [54], attributed to cooperative intramolecular hydrogen bonding. This location is comparable to that of the band at $3345 \mathrm{~cm}^{-1}$ observed in crystalline CHL, particularly considering the different aggregation states (liquid vs. crystalline). Another analogous (polymeric) 1,3-diol is atactic poly(vinyl alcohol), a crystalline polymer in which the $\mathrm{OH}$ stretching band is located at $3350 \mathrm{~cm}^{-1}$ [56], though in this case both intramolecular and intermolecular hydrogen bonding can occur in the crystalline phase [57]. In summary, the two $\mathrm{OH}$ stretching bands observed in crystalline CHL can be feasibly assigned assuming the conformation assumed by Chatterjee, but neither of them is compatible with the atomic coordinates provided for the $\mathrm{OH}$ groups by Acharya.

Upon melting, only a broad envelope can be observed for the $\mathrm{OH}$ stretching band, indicating molecular disorder and a broad range of interaction strengths. 


\subsection{Intermolecular Interactions and Lattice Energy of crystalline CHL}

Intermolecular interactions and Lattice energies have been computed for the crystalline models proposed by Chatterjee and Acharya using CrystalExplorer v17.5. When the original CIF files (see experimental) are used to build large molecular clusters, the QM calculations fail because of the odd locations for the $\mathrm{H}$ atoms. Hence, the coordinates of the hydrogen atoms have first been refined with the Firefly QM package at the B3LYPD3/DZP level. Small clusters consisting of chains of three hydrogen bonded molecules with fixed coordinates for the heavy atoms have been used for this task. These results have been used to obtain refined CIF files, that have been used in CrystalExplorer to build molecular clusters including all the molecules with interatomic distances below $25 \AA$ (relative to any atom in the central molecule). Further details can be found in the supplementary information. The interaction energies have been calculated using the CEB3LYP model, and have been used to compute the lattice energy, Elat ${ }^{\text {CE-B3LYP }}$, using Eq. 2:

$$
E_{l a t}^{C E-B 3 L Y P}=\frac{1}{2} \sum_{R_{A B}<R} N_{A B} E_{t o t}^{A B}
$$

where the summation extends to all the non-equivalent $\mathrm{AB}$ pairs located below the cutoff radius, $\mathrm{E}_{\text {tot }}{ }^{\mathrm{AB}}$ is the total interaction energy for each non-equivalent $\mathrm{AB}$ pair and $\mathrm{N}_{\mathrm{AB}}$ is the number of equivalent $\mathrm{AB}$ pairs with the same interaction energy, $\mathrm{E}_{\mathrm{tot}} \mathrm{AB}$.

Table 1 shows the interaction energies obtained in the QM calculations of the clusters using the CE-B3LYP model. Interaction energies between equivalent molecules have been explicitly listed only for the molecular pairs closer than $10 \AA$ (measured from the centroids), while the remaining, less relevant interaction energies have been grouped together in a single entry (the complete table can be seen in the supplementary information). As can be seen, the strongest interactions in the structure of Chatterjee are established with the closest 4 neighbours (see Table 1 and Fig. 4). The highest energy ($84.4 \mathrm{~kJ} / \mathrm{mol}$ ) corresponds to the $\mathrm{AB}$ pair linked by two reciprocal $\mathrm{N}-\mathrm{H} \cdots \mathrm{O}-\mathrm{H}$ hydrogen bonds, while each of the two equivalent $\mathrm{AB}$ pairs linked by $\mathrm{O}-\mathrm{H} \cdots \mathrm{O}=\mathrm{C}$ interactions contribute with $-44.2 \mathrm{~kJ} / \mathrm{mol}$. The remaining interaction energy, $-52.6 \mathrm{~kJ} / \mathrm{mol}$, is achieved with the closest molecule. In this case, the detailed results show a relatively large 
dispersive interaction accompanied by a low repulsive contribution, suggesting that the interaction energy can be attributed to a favourable molecular packing. However, in the

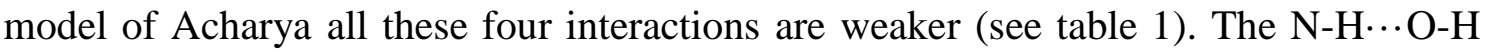
interaction is almost halved, probably because of the bifurcated nature of the interaction (the $\mathrm{O}$ atom also accepts an intramolecular $\mathrm{O}-\mathrm{H} \cdots \mathrm{O}-\mathrm{H}$ bond). Since this model does not present $\mathrm{O}-\mathrm{H} \cdots \mathrm{O}=\mathrm{C}$ interactions, the interaction energies between the corresponding $\mathrm{AB}$ pairs drops to nearly zero, and finally the interaction energy of the closest AB pairs also decreases. As a consequence, the lattice energy calculated for the model of Chatterjee is about $60 \mathrm{~kJ} / \mathrm{mol}$ lower than the one calculated for the model of Acharya. Since this value is much larger than the conformational energy difference between the conformers of Acharya and Chatterjee (see next section), this QM analysis also supports the structure proposed by Chatterjee, in agreement with the spectroscopic analysis performed for the $\mathrm{OH}$ stretching band.

Table 1. Interaction energies and lattice energies calculated for the models of Chatterjee and Acharya on large molecular clusters $\left(R_{\text {all atoms }}<25 \AA\right)$.

\begin{tabular}{|c|c|c|c|c|c|c|c|c|c|}
\hline \multicolumn{5}{|c|}{ Chatterjee } & \multicolumn{5}{|c|}{ Acharya } \\
\hline $\mathrm{N}_{\mathrm{AB}}$ & $\begin{array}{l}\text { Symmetry } \\
\text { Operation }\end{array}$ & $\begin{array}{l}\mathrm{R}_{\mathrm{AB}} \\
(\AA)\end{array}$ & $\begin{array}{c}\mathrm{E}_{\mathrm{tot}}^{\mathrm{AB}} \\
(\mathrm{kJ} / \mathrm{mol})\end{array}$ & $\begin{array}{c}\Sigma \mathrm{N}_{\mathrm{AB}} \cdot \mathrm{E}_{\mathrm{tot}}{ }^{\mathrm{AB}} \\
(\mathrm{kJ} / \mathrm{mol})\end{array}$ & $\mathrm{N}_{\mathrm{AB}}$ & $\begin{array}{l}\text { Symmetry } \\
\text { Operation }\end{array}$ & $\mathrm{R}_{\mathrm{AB}}(\AA)$ & $\begin{array}{c}\mathrm{E}_{\mathrm{tot}}^{\mathrm{AB}} \\
(\mathrm{kJ} / \mathrm{mol})\end{array}$ & 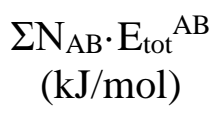 \\
\hline 1 & $\mathrm{x},-\mathrm{y},-\mathrm{z}$ & 5.87 & -52.6 & -52.6 & 1 & $\begin{array}{l}-x, y,- \\
z+1 / 2\end{array}$ & 5.88 & -43.4 & -43.4 \\
\hline 2 & $\mathrm{x}, \mathrm{y}, \mathrm{z}$ & 7.32 & -44.2 & -88.4 & 2 & $\mathrm{x}, \mathrm{y}, \mathrm{z}$ & 7.34 & 1.7 & 3.4 \\
\hline 1 & $-\mathrm{x}, \mathrm{y},-\mathrm{z}+1 / 2$ & 7.35 & -84.4 & -84.4 & 1 & $\mathrm{x},-\mathrm{y},-\mathrm{z}$ & 7.35 & -44.9 & -44.9 \\
\hline 2 & $\begin{array}{c}-\mathrm{x}+1 / 2 \\
\mathrm{y}+1 / 2,-\mathrm{z}+1 / 2\end{array}$ & 7.46 & -7.4 & -14.8 & 2 & $\begin{array}{c}x+1 / 2,- \\
y+1 / 2,-z\end{array}$ & 7.48 & -12.2 & -24.4 \\
\hline 1 & $\mathrm{x},-\mathrm{y},-\mathrm{z}$ & 8.28 & -7.6 & -7.6 & 1 & $\begin{array}{l}-\mathrm{x}, \mathrm{y},- \\
\mathrm{z}+1 / 2\end{array}$ & 8.3 & -13.5 & -13.5 \\
\hline 2 & $\begin{array}{c}\mathrm{x}+1 / 2, \mathrm{y}+1 / 2 \\
\mathrm{z}\end{array}$ & 9.48 & -11.2 & -22.4 & 2 & $\begin{array}{c}x+1 / 2, \\
y+1 / 2, z\end{array}$ & 9.51 & -8.3 & -16.6 \\
\hline 2 & $\begin{array}{c}\mathrm{x}+1 / 2, \mathrm{y}+1 / 2 \\
\mathrm{z}\end{array}$ & 9.48 & -6.2 & -12.4 & 2 & $\begin{array}{c}x+1 / 2, \\
y+1 / 2, z\end{array}$ & 9.51 & -4.9 & -9.8 \\
\hline $369 *$ & - & $10-35$ & - & -76.3 & $379 *$ & - & $10-35$ & - & -88.9 \\
\hline & & & ${ }_{\text {lat }}{ }^{\text {CE-B3LYP }}$ & -179.4 & & & & lat ${ }^{\text {CE-B3LYP }}$ & -119.0 \\
\hline
\end{tabular}

* The AB pairs in this row are not equivalent 


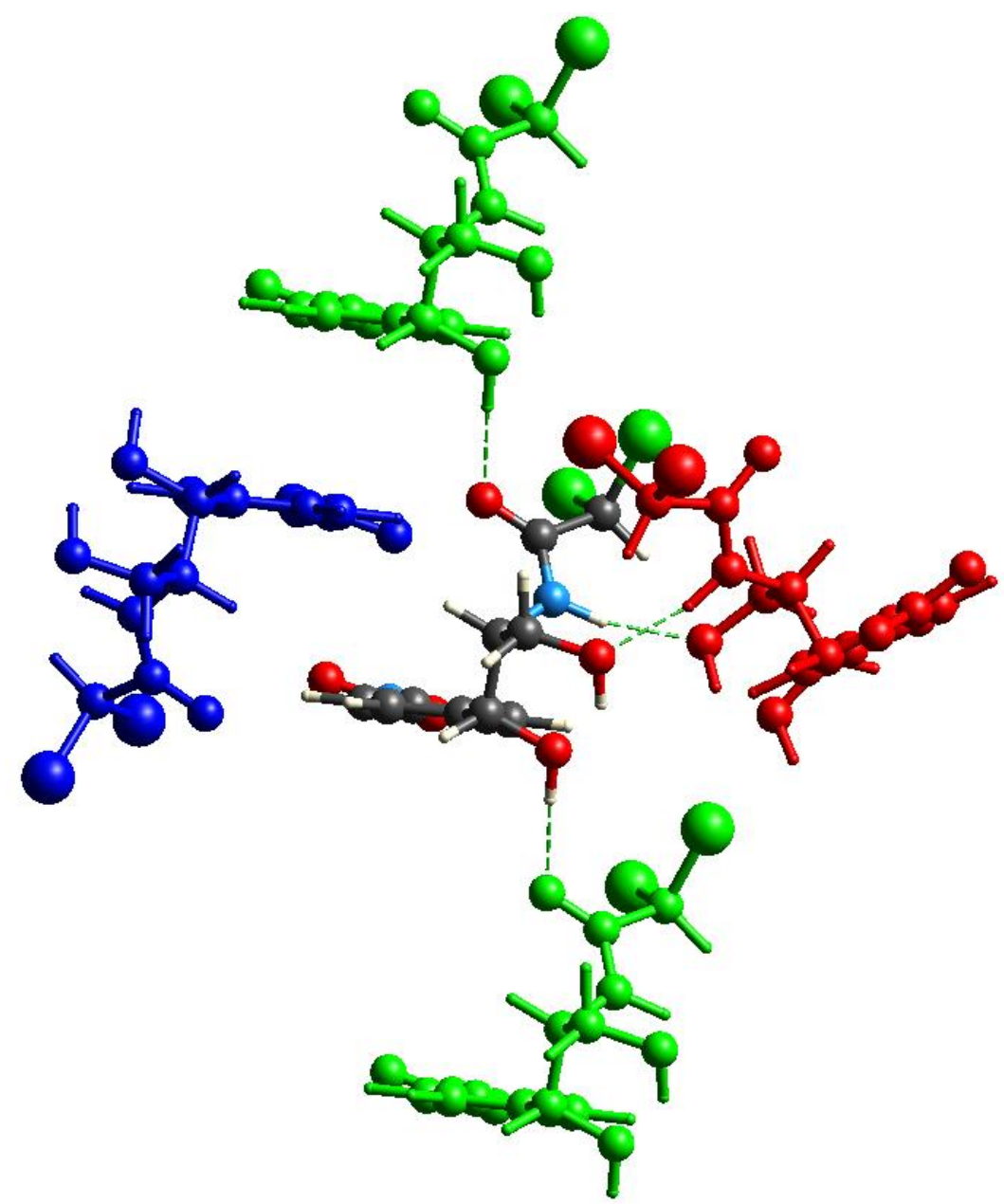

Figure 4. The four stronger interacting $\mathrm{AB}$ pairs computed for the crystalline structure of $\mathrm{CHL}$ proposed by Chatterjee and the intermolecular hydrogen bonding interactions, showing the two reciprocal $\mathrm{N}-\mathrm{H} \cdots \mathrm{O}-\mathrm{H}$ interactions (with the red molecule) and the $\mathrm{O}-\mathrm{H} \cdots \mathrm{O}=\mathrm{C}$ interactions (with the two equivalent green molecules).

\subsection{FTIR analysis of molten CHL and free CHL in solution.}

The Amide I stretching region of CHL is shown in Figure 5. Pure crystalline CHL displays a narrow peak at about $1687 \mathrm{~cm}^{-1}$. Upon melting the peak shows an unexpectedly large broadening (its half height width reaches $\sim 40 \mathrm{~cm}^{-1}$ ), and maintains its location instead of shifting to higher wavenumbers as expected. Moreover, after quenching to room temperature the peak red shifts to about $1679 \mathrm{~cm}^{-1}$, at even lower wavenumbers than the initial crystalline $\mathrm{C}=\mathrm{O}$ band. These changes suggest the formation upon melting of a new conformer located at lower wavenumbers, since the $\mathrm{O}-\mathrm{H} \bullet \bullet \mathrm{O}=\mathrm{C}$ interactions in the amorphous phase can hardly be stronger than in the crystalline phase. Second derivative spectroscopy of quenched $\mathrm{CHL}$ at room temperature reveals two components 
located at about 1690 and $1675 \mathrm{~cm}^{-1}$, where the lower wavenumber band can be attributed to the new conformer formed upon melting.

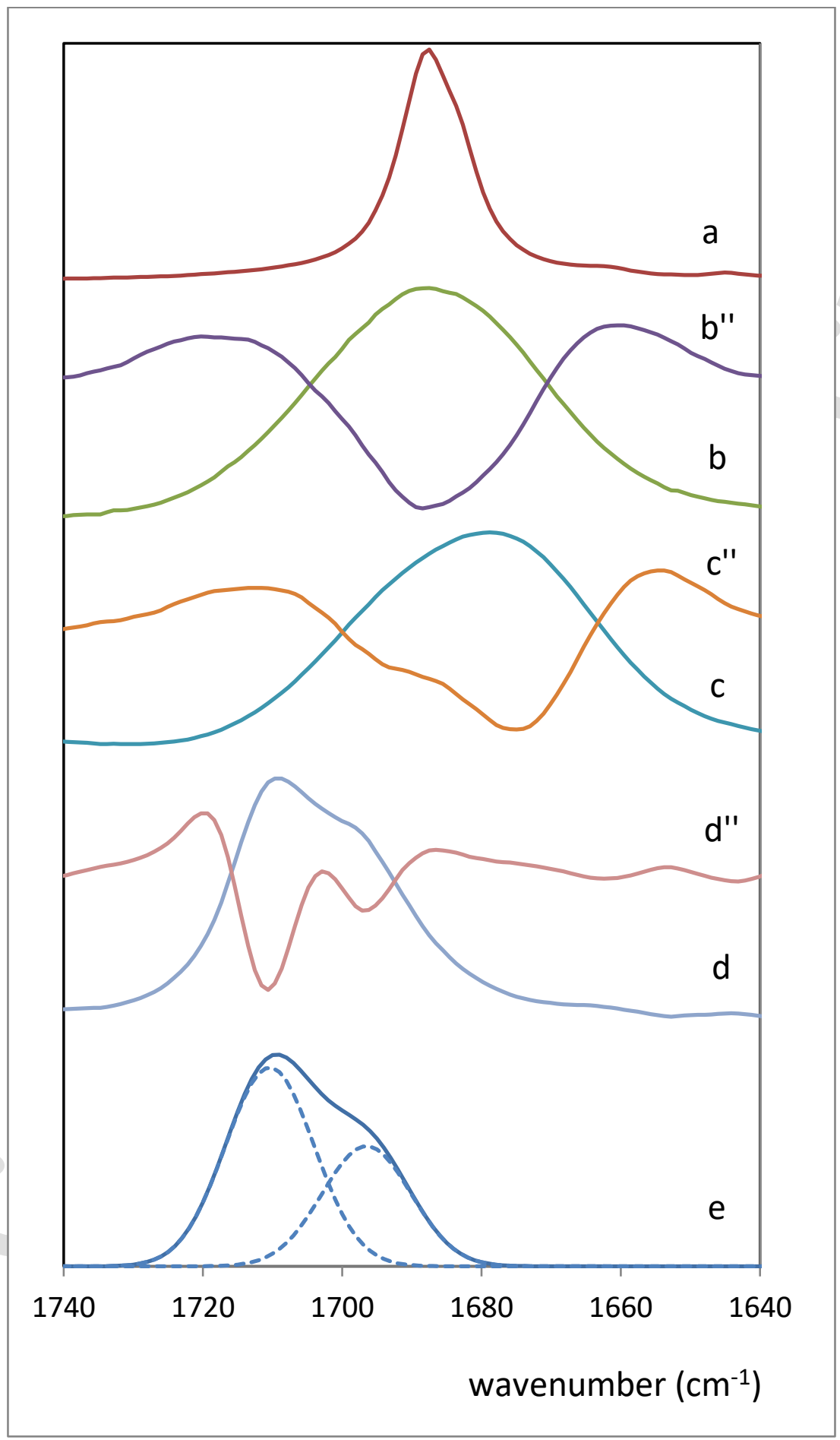

Figure 5. Amide stretching region of CHL and second derivatives ('") of: a) crystalline CHL at $40{ }^{\circ} \mathrm{C}$; b) molten $\mathrm{CHL}$ at $160^{\circ} \mathrm{C}$; c) supercooled $\mathrm{CHL}$ at $40^{\circ} \mathrm{C}$; d) $\mathrm{CHL}$ in acetonitrile solution (1 wt\%); e) computed spectrum of CHL in acetonitrile solution at the B3LYP-D3/6$311 \mathrm{G}(2 \mathrm{~d}, \mathrm{p}) / \mathrm{SMD}$ level of theory (scaling factor 0.9756). 
Figure 5 also displays the spectrum of CHL in dilute acetonitrile (ACN) solution (1 wt $\%)$. As can be seen, the $\mathrm{C}=\mathrm{O}$ stretching band of $\mathrm{CHL}$ in dilute solution shows two components located at about 1697 and $1710 \mathrm{~cm}^{-1}$. The occurrence of other split bands in this spectrum suggests the presence of different conformers over Fermi resonance as the origin of the splitting. Carbonyl groups containing electronegative atoms in the alpha carbon (the two $\mathrm{Cl}$ atoms in the case of $\mathrm{CHL}$ ) are known to show conformational sensitivity $[58,18]$. Most studies dealing with these effects have focused however on $\mathrm{CO}-\mathrm{CH}_{2}-\mathrm{X}$ structures (where $\mathrm{X}$ is an electronegative atom such as $\mathrm{F}, \mathrm{O}, \mathrm{N}, \mathrm{Cl}, \mathrm{Br}, \mathrm{S}, \mathrm{I}$ ) [59, 60, 61, 62]. The presence of a single electronegative atom in the alpha Carbon is known to modify the typical threefold rotational isomerism around the $\mathrm{CO}-\mathrm{C} \alpha$ bond (anti, gauche \pm ) to a twofold one (anti, syn) [18, 59, 60] and shift the location of the $\mathrm{C}=\mathrm{O}$ stretching band [63]. This hypothesis is analyzed in the next section.

\subsection{Quantum Mechanical calculations of free CHL molecules.}

Assuming that the amide bond prefers the anti conformation, CHL contains seven potential rotatable bonds (see scheme 2). The first four dihedrals determine to a large extent the overall shape of the molecule, while the remaining three have a minor effect. According to Bustard [14] and Höltje [15], CHL presents two predominant conformers in solution (see table 2 for conformational details), where conformer $\mathbf{1}$ is unable to stablish any intramolecular HB since $\phi_{3}=180^{\circ}$. However, these results are in disagreement with the earlier analysis of Jardetzky [12], who examined the NMR spectra of CHL solutions in different solvents to conclude the existence of a single predominant conformer stabilized by an intramolecular HB. FTIR spectroscopy also supports the existence of intramolecular HBs in the free CHL molecules in solution [16]. A definitive study has been claimed [1]. 


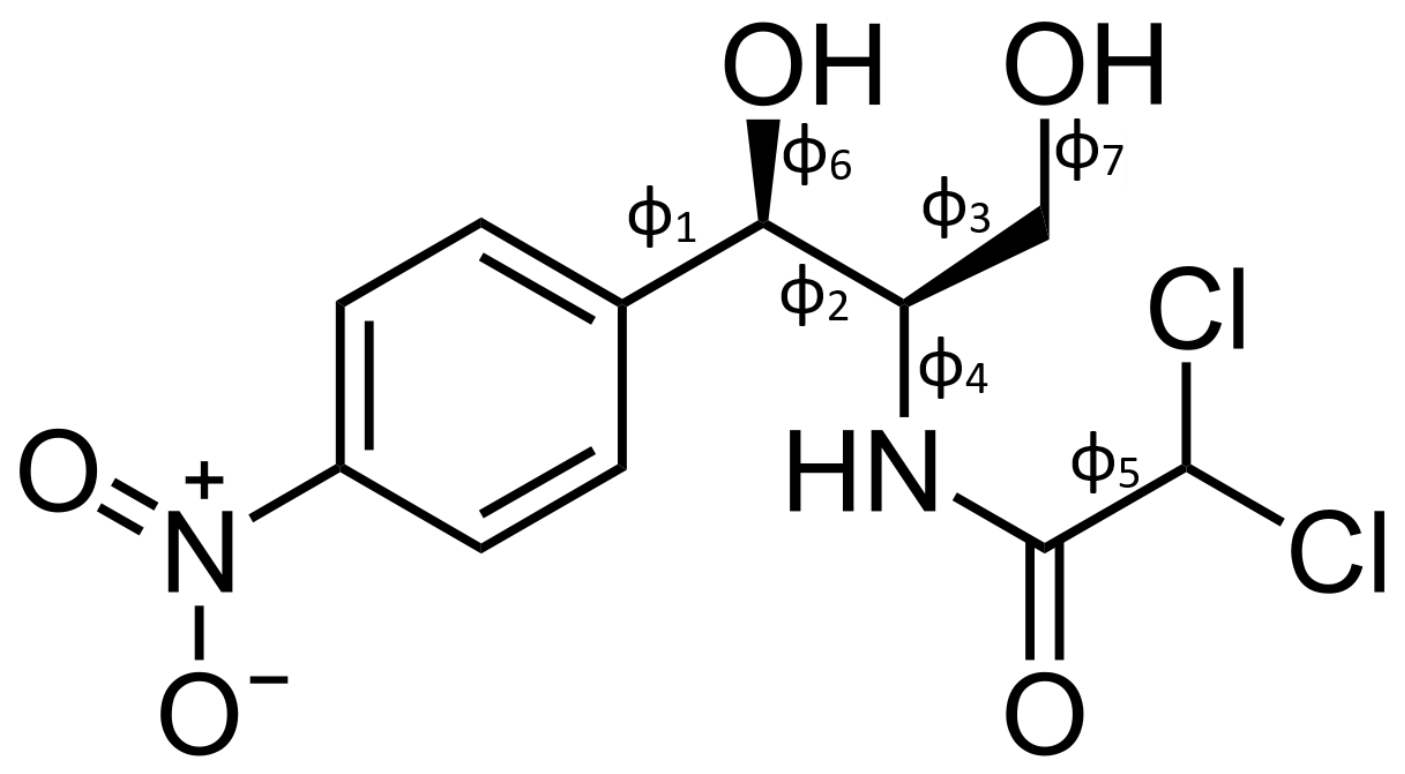

Scheme 2. The seven rotatable bonds in CHL.

Table 2. Dihedrals proposed by Höltje [15] for the two most stable conformers of CHL in solution. The dihedrals of the crystalline conformers proposed by Chatterjee [10] and Acharya [11] are also included for comparison.

\begin{tabular}{cccccc}
\hline Dihedral & $\begin{array}{c}\text { Reference } \\
\text { atoms }\end{array}$ & Conf. 1 & Conf. 2 & Chatterjee & Acharya \\
\hline$\phi_{1}$ & $\mathrm{C}_{\mathrm{a}} \mathrm{C}_{\mathrm{a}} \mathrm{CC}$ & 90 & 90 & 91 & 95 \\
$\phi_{2}$ & $\mathrm{C}_{\mathrm{a}} \mathrm{CCN}$ & -60 & -60 & -55 & -58 \\
$\phi_{3}$ & $\mathrm{CCCO}$ & 180 & 60 & 72 & 70 \\
$\phi_{4}$ & $\mathrm{HCNH}$ & 180 & 180 & -162 & 175 \\
$\phi_{5}$ & $\mathrm{OCCH}$ & 60 & 60 & -171 & -162 \\
$\phi_{6}$ & $\mathrm{C}$ & -60 & 180 & -18 & 146 \\
$\phi_{7}$ & $\mathrm{CCOH}$ & -60 & 30 & -42 & -124 \\
& & & & &
\end{tabular}

Hence, the conformational behavior of CHL in solution has been revisited here. The task has been simplified considering the proven results indicated below. The minimum of $\phi_{1}$ is known to be at about $90^{\circ}[64,65]$. Bustard [14] concluded using NMR spectroscopy that $\phi_{4}$ adopts the anti conformation. In addition, $\phi_{5}$ is known to adopt both the anti and syn conformations in condensed phases [18]. Hence, $\phi_{1}=90^{\circ}, \phi_{4}=180^{\circ}$ and $\phi_{5}=0^{\circ}, 180^{\circ}$ 
have been assumed here. Regarding $\phi_{2}, \phi_{3}, \phi_{6}$ and $\phi_{7}$ the anti and gauche \pm rotamers have been considered. Therefore, 162 molecular models have been built and optimized in acetonitrile solution at the B3LYP-D3/DZP/Onsager level of theory. The six conformers of lower energy have been identified and reoptimized at the B3LYP-D3/def2-TZVP(f)/Onsager level of theory using tight convergence criteria (all of them are true minima as confirmed by the absence of negative frequencies in the vibrational analyses at the same level of theory).

Table 3 shows the dihedral angles for the 6 conformers of lower energy obtained in this conformational analysis. As can be seen, dilute CHL solutions in acetonitrile should contain mainly conformers I and II in similar amounts (see Fig. 6 for geometries). These two conformers adopt similar geometries (they only differ in the opposite orientation of the dichloromethyl group determined by $\phi_{5}$, see Fig 6) and show similar energies. Similarly to conformers I and II, the remaining conformers also appear arranged pairwise in the energy scale, differing in opposite $\phi_{5}$ values. Conformers I-IV present an intramolecular hydrogen bond, while this interaction is not possible in conformers $\mathbf{V}$ and VI since $\phi_{3}$ adopts the anti conformation. Optimizations have also lead to a Chaterjeelike conformer (not listed in table 3) with $\Delta \mathrm{E} \sim 35 \mathrm{~kJ} / \mathrm{mol}$. Notice however that this computed conformer presents a simple intramolecular hydrogen bond instead of the one enhanced by the cooperativity effects occurring in the crystalline phase, that should stabilize it additionally. In any case, the strong intermolecular interactions in the crystalline phase seem to be of crucial importance in the selection of the ordered geometry. 
Table 3. Optimized geometry dihedrals and population percentages for the six lower energy conformers of CHL in acetonitrile solution at the B3LYP-D3/def2-TZVP(-f)/Onsager level of theory.

\begin{tabular}{ccccccc}
\hline Dihedral & I & II & III & IV & V & VI \\
\hline$\phi_{1}\left(\mathrm{C}_{\mathrm{a}} \mathrm{C}_{\mathrm{a}} \mathrm{CC}\right)$ & 102 & 105 & 112 & 106 & 101 & 101 \\
$\phi_{2}\left(\mathrm{C}_{\mathrm{a}} \mathrm{CCN}\right)$ & -64 & -67 & -53 & -64 & -61 & -64 \\
$\phi_{3}(\mathrm{CCCO})$ & 64 & 65 & -41 & -50 & -176 & -179 \\
$\phi_{4}(\mathrm{HCNH})$ & 153 & 152 & 164 & 161 & 154 & 146 \\
$\phi_{5}(\mathrm{OCCH})$ & 42 & 160 & 40 & 160 & 44 & 162 \\
$\phi_{6}\left(\mathrm{C}_{\mathrm{a}} \mathrm{COH}\right)$ & 166 & 169 & -161 & -153 & -158 & -153 \\
$\phi_{7}(\mathrm{CCOH})$ & 176 & 177 & -170 & -176 & -179 & 180 \\
$\Delta \mathrm{E}(\mathrm{kJ} / \mathrm{mol})$ & 0 & 0.604 & 15.82 & 18.84 & 27.08 & 27.07 \\
$\Delta \mathrm{G}^{\mathrm{o}}(\mathrm{kJ} / \mathrm{mol})$ & 0.352 & 0 & 13.64 & 13.90 & 20.86 & 21.05 \\
$\mathrm{~N}_{\mathrm{i}} / \mathrm{N}(\%)$ & 46.25 & 53.31 & 0.22 & 0.20 & 0.01 & 0.01
\end{tabular}
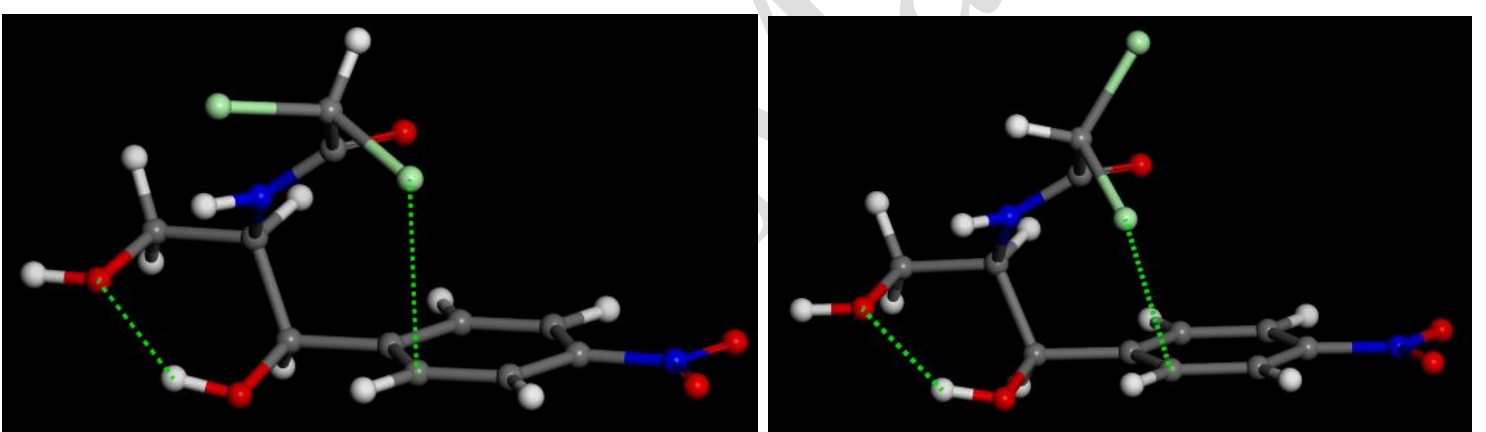

Figure 6. Equilibrium geometries for conformers I (left) and II (right) in acetonitrile at the B3LYP-D3/def2-TZVP(-f)/Onsager level of theory.

Compared to previous reports, our results agree with the existence of intramolecular hydrogen bonding as concluded by Jardetzky [12], but reveal the existence of two stable conformers instead of only one. His derivation of a single conformer can be rationalized considering that conformers I and II share the major part of the geometry (they only differ in the rotation of the dichloromethyl group). In addition, our results discard the existence of the conformer devoid of intramolecular hydrogen bonds reported by Bustard (conformer 1 in table 2) [14]; in fact, the free energy of the conformers with $\phi_{3}=180^{\circ}$ (conformers $\mathbf{V}$ and $\mathbf{V I}$ in table 3 ) is about $20 \mathrm{~kJ} / \mathrm{mol}$ larger than that of conformer $\mathbf{I}$. In 
this case, the crude approach used by the author to analyze the relative prevalence of $\phi_{3}(\mathrm{CCCO})$ is the most probable source of error $[66,67]$.

According to table 3, only conformers I and II should prevail in acetonitrile solution. Hence these geometries have been further optimized using the Solvation Model based on solute electron Density (SMD) model recently developed by Thrular et al [25, 68]. This model corrects some of the shortcomings of previous Continuum Solvation models and has been reported to improve their overall performance [27, 69]. The specific details of the computational protocol adopted in the parametrization have been kept in this work in order to maintain the balance between electrostatic and nonelectrostatic components [70, 71]. The 6-31G(d) (used in the original parametrization [25]) and the 6-311G(2d,p) basis sets have been chosen here. Further details on the calculations can be found in the supplementary information. Table 4 lists the dihedral angles, dipole moments, energies and populations of conformers I and II in acetonitrile solution computed at the B3LYPD3/6-311G(2d,p)/SMD level. Both geometries have been confirmed to be true minima through vibrational analyses at the same level of theory. As can be seen, the results are very similar to those obtained before using the Onsager model, indicating that the spherical cavity assumption works satisfactorily for the CHL molecule. The SMD model also predicts the existence of these two conformers in similar amounts, conformer II being again the most stable. Moreover, the locations computed for the $\mathrm{C}=\mathrm{O}$ stretching band of conformers I and II at the B3LYP-D3/6-311G(2d,p)/SMD level of theory using a 0.9756 scale factor are respectively 1696.5 and $1710.4 \mathrm{~cm}^{-1}$. These values are in excellent agreement with the two bands experimentally observed in the $\mathrm{C}=\mathrm{O}$ stretching region (see Fig. 5), located at about 1697 and $1710 \mathrm{~cm}^{-1}$ using second derivative spectroscopy. The $\mathrm{C}=\mathrm{O}$ stretching region has been simulated and plotted in Fig. 5 (the absorptivity ratio obtained in the computations, $\varepsilon_{\mathrm{I}} / \varepsilon_{\mathrm{II}}=1.12$, has also been considered). As can be seen, the conformational analysis performed in this section provides an excellent description of the experimental $\mathrm{C}=\mathrm{O}$ stretching region. The computations performed with the simpler 6-31G(d) are qualitatively similar, but this level of theory predict a larger relative population for Conformer II (76 mol \%). Finally, it is worth to notice that the blue shift relative to the location of aliphatic secondary amides (absorbing at about $\left.1691 \mathrm{~cm}^{-1}[72,63]\right)$ is larger for conformer II ( $\phi_{5}(\mathrm{HCCO})$ in anti conformation) because the chlorine atoms are closer to the $\mathrm{C}=\mathrm{O}$ group and the electronic interaction between these moieties is stronger. 
In order to discuss the effect of the environment, the conformational analysis has also been carried out in vacuum (see table 4). Three major conformers, termed A, B and C, have been confirmed to be stable geometries according to the lack of negative frequencies at the B3LYP-D3/def2-TZVP(-f) level. Excepting $\phi_{5}$, which adopts the syn instead of the anti dihedral, the $\mathrm{B}$ and $\mathrm{C}$ structures resemble the conformers proposed by Chatterjee and Acharya respectively. Since both structures show similar energies, the intramolecular O$\mathrm{H} \cdots \mathrm{OH}$ bond in vacuum does not show any preferred layout. Conformer $\mathrm{A}$ is actually similar to $\mathrm{C}$, but $\phi_{7}$ changes to gauche to allow the formation of an intramolecular $\mathrm{O}$ $\mathrm{H} \cdots \mathrm{Cl}$ hydrogen bond to become the most stable structure (see also additional information). As can be seen, when gaseous CHL is introduced in acetonitrile solution, only the most polar conformer remains prevalent (conformers C and I are identical), suggesting the importance of the electrostatic interactions in solution. Finally, the vacuum analysis has also revealed the unexpected occurrence of conformers (not included in table 4 ) in which $\phi_{5}$ adopts the anti conformation (the dichloroacetyl group is known to prefer exclusively the syn conformation in vacuum [18]).

Table 4. Optimized geometry dihedrals, dipole moments and population percentages for conformers I and II in vacuum at the MP2/def2-TZVPP level of theory and in acetonitrile at the B3LYP-D3/6-311G(2d,p)/SMD level of theory.

\begin{tabular}{|c|c|c|c|c|c|}
\hline \multirow[b]{2}{*}{ Dihedral } & \multicolumn{3}{|c|}{ Vacuum } & \multicolumn{2}{|c|}{ Acetonitrile } \\
\hline & $\mathbf{A}$ & $\mathbf{B}$ & $\mathbf{C}$ & I & II \\
\hline$\phi_{1}\left(\mathrm{C}_{\mathrm{a}} \mathrm{C}_{\mathrm{a}} \mathrm{CC}\right)$ & 108 & 87 & 98 & 102 & 98 \\
\hline$\phi_{2}\left(\mathrm{C}_{\mathrm{a}} \mathrm{CCN}\right)$ & -66 & -53 & -62 & -62 & -61 \\
\hline$\phi_{3}(\mathrm{CCCO})$ & 60 & 78 & 61 & 64 & 64 \\
\hline$\phi_{4}(\mathrm{HCNH})$ & 137 & 148 & -174 & 172 & 175 \\
\hline$\phi_{5}(\mathrm{OCCH})$ & -19 & -4 & -26 & 28 & -177 \\
\hline$\phi_{6}\left(\mathrm{C}_{\mathrm{a}} \mathrm{COH}\right)$ & 170 & -55 & 169 & 164 & 163 \\
\hline$\phi_{7}(\mathrm{CCOH})$ & 77 & -62 & 175 & 177 & -176 \\
\hline$\mu(D)$ & 6.1 & 6.1 & 9.2 & 12.4 & 14.0 \\
\hline$\Delta \mathrm{E}(\mathrm{kJ} / \mathrm{mol})$ & 0 & 0 & 2.5 & 0.22 & 0 \\
\hline$\Delta \mathrm{G}^{\mathrm{o}}(\mathrm{kJ} / \mathrm{mol})^{*}$ & 0 & 1.1 & 2.1 & 1.52 & 0 \\
\hline $\mathrm{N}_{\mathrm{i}} / \mathrm{N}(\%)^{*}$ & 48.4 & 30.8 & 20.8 & 35.1 & 64.9 \\
\hline
\end{tabular}


In order to rationalize the conformational behavior of the dichloroacetyl group of CHL, the relaxed potential energy surface (PES) has been scanned around $\phi_{5}$ both in vacuum and in acetonitrile solution using the equivalent $\mathbf{C}$ and $\mathbf{I}$ geometries (see Figure 7). Since the stable conformers in both media (see Figure 6) show chlorine atoms close to the aromatic ring, their geometries have been inspected for the occurrence of intramolecular $\mathrm{C}-\mathrm{Cl} \cdots \pi$ interactions. These contacts, termed halogen bonds, are widespread among pharmaceutical compounds since about $40 \%$ drugs currently on the market or in clinical trials are halogenated [73]. However, they have been usually overlooked because their importance in, for example, crystals and biological systems, has been only recently established $[74,75]$. The halogen bond is a highly directional and specific non-covalent interaction, analogous to the hydrogen bond. It is formed between a halogen and a proximal halogen-bond acceptor (such as $\mathrm{O}, \mathrm{N}, \mathrm{S}$, and aromatic ring) [73, 75]. In the case of CHL, the conformation of the molecular skeleton of CHL deviates the Chlorine atoms to one side of the aromatic ring instead of letting them to interact freely with the ring. The analysis of the geometries obtained during the PES scans shows that the chlorine atoms get close to the two aromatic Carbon atoms in the $>\mathrm{C}_{\mathrm{a}}-\mathrm{H}$ groups at one side of the ring. Hence, the length of the $\mathrm{Cl} \cdots \pi$ bond has been measured as the average distance between the $\mathrm{Cl}$ atom involved in the bond and the two aromatic $>\mathrm{C}_{\mathrm{a}}-\mathrm{H}$ Carbons at the closer side of the ring. As can be seen in Fig. 7 , in vacuum the minimum distances $\left(\mathrm{d}_{\mathrm{Cl}-\pi}=3.86 \AA\right.$ and $3.88 \AA$ ) occur at $\phi_{5} \sim 50^{\circ}$ and $\sim 150^{\circ}$ respectively, suggesting the formation of two different $\mathrm{C}-\mathrm{Cl} \cdots \pi$ halogen bonds. The occurrence of these interactions may be further investigated using Natural Bond Orbitals (NBO) theory [76]. The observed distances are in good agreement with those reported for the complexes formed between wild-type enzymes and chlorobenzyl cyanide [73], and support the occurrence of intramolecular C$\mathrm{Cl} \cdots \pi$ interactions in $\mathrm{CHL}$. The halogen bond occurring at about $50^{\circ}$ seems responsible for the asymmetry of the PES surface in vacuum, which is skewed to positive dihedrals. The halogen bond occurring at about $150^{\circ}$ seems responsible for the unexpected minimum occurring at about $150^{\circ}$ in vacuum. 


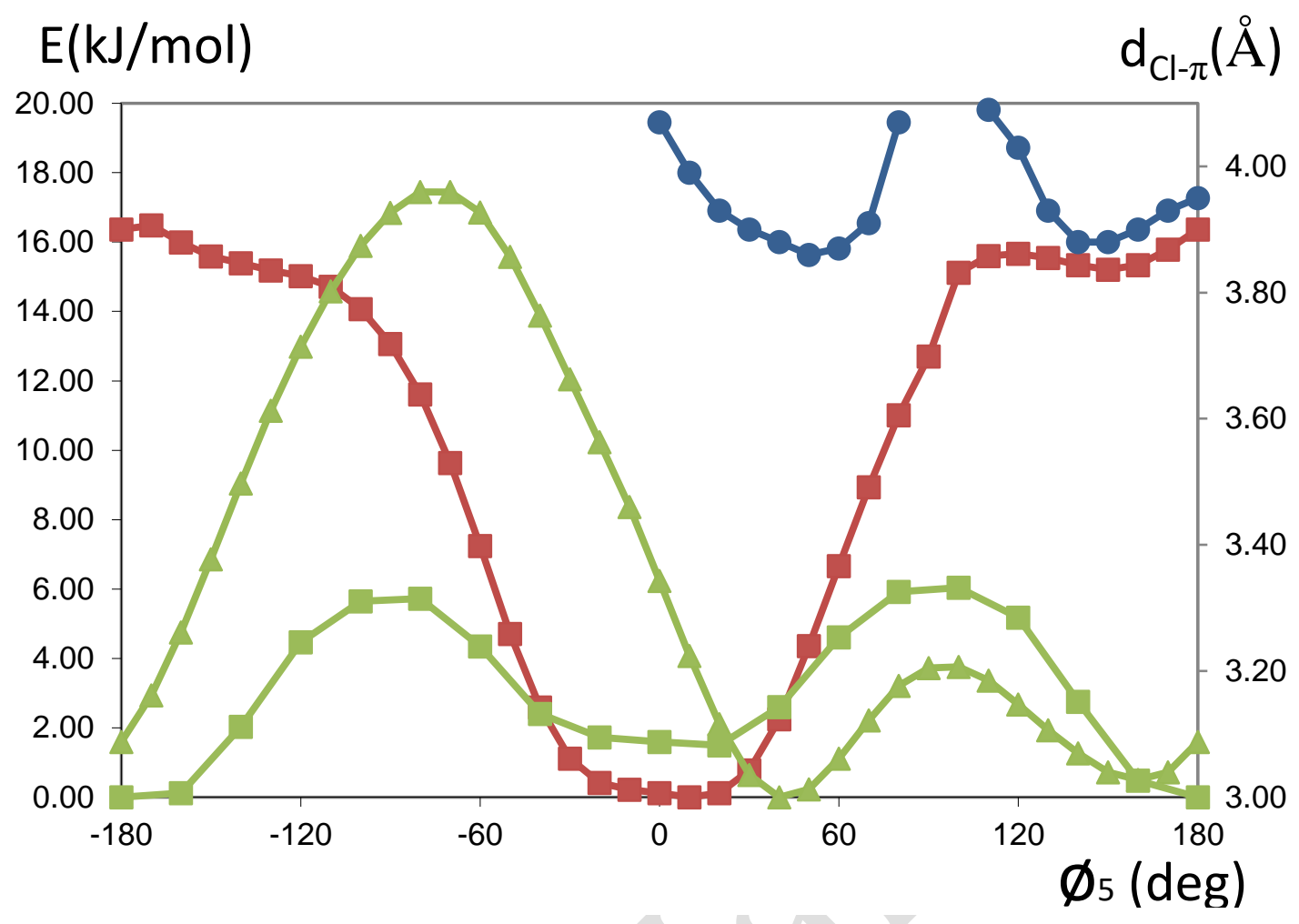

Figure 7. Relaxed PES scans around $\phi_{5}$ (HCCO dihedral) and halogen bonding distances: ( $\square$ ) Vacuum PES for conformer C at the B3LYP-D3/def2-TZVP(-f) level, ( $\triangle$ ) Acetonitrile PES at the B3LYP-D3/def2-TZVP(-f)/Onsager level, ( $\square$ ) Acetonitrile PES at the B3LYP/6$31 \mathrm{G}(\mathrm{d}) / \mathrm{SMD}$ level, $(\bullet)$ distance between the aromatic ring and the closest chlorine atom in vacuum.

Figure 7 also displays the PES scans computed in acetonitrile solution using both the Onsager and SMD models. In spite of the different shapes, both curves show two minima corresponding to the syn and anti conformers. Compared to the PES curve in vacuum, acetonitrile strongly stabilizes conformer II, and its energy becomes similar to that of conformer I. This strong stabilization can be accounted for using the classical Onsager model, which attributes the stabilization of polar conformers in solution to favorable electrostatic interactions with the solvent $[23,77]$. According to this model, the difference in the free energy of solvation between two conformers of the same size is given by equation 3:

$$
\Delta\left(\Delta G_{\text {solv }}^{o}\right)=\frac{-N_{A}}{4 \pi \varepsilon_{0}} \frac{\varepsilon_{r}-1}{2 \varepsilon_{r}+1} \frac{\mu_{A}^{2}-\mu_{B}^{2}}{a^{3}}
$$

where $N_{A}$ is the Avogadro number, $\varepsilon_{0}$ is the permittivity of vacuum, $\varepsilon_{\mathrm{r}}$ is the relative permittivity and $\mu$ is the dipole moment. The stabilizing contribution arising from electrostatic interactions with the solvent depends on the stabilizing character of the 
medium, given by the Onsager term, $\left(\varepsilon_{\mathrm{r}}-1\right) /\left(2 \varepsilon_{\mathrm{r}}+1\right)$, and on the difference of the square of the dipole moments. In vacuum, the anti conformer does not suffer any electrostatic stabilizing effect from the solvent because the Onsager term is zero, and the dichloroacetyl moiety prefers the syn conformation. However, in acetonitrile solution, the more polar anti conformer (see table 4) is strongly stabilized by the solvent up to the point where the energies of the syn and the anti conformers become similar. It must be noticed that the classical Eq. 3 does not account for the distortion of the wavefunction occurring when the conformer is introduced in the polar medium (which causes the increase in dipole moment observed in table 4), and does not therefore account for the corresponding variations of electronic energy. It is therefore a less accurate approach to the problem than the SCRF method used in this paper [43, 78], and is introduced here only for a qualitative discussion of the results.

In summary, the PES scans in Figure 7 indicate that both the anti and the syn conformers are stable conformers regardless of the medium. In media of high polarity, both are present in similar amounts, but in solvents of lower dielectric constant, conformer $\mathbf{I}$ is expected to dominate over conformer II. This situation is actually observed in molten CHL, though in this case the hydrogen bonding ability of the conformers could also affect the conformational equilibrium.

\section{Conclusions}

The conformational behavior of CHL has been has been revisited in order to enlighten the contradictory results reported so far. The analysis of the $\mathrm{X}-\mathrm{H}$ stretching region indicates that CHL crystallizes in the conformation proposed by Chatterjee [10], and not in the conformation proposed by Acharya [11]. The $\mathrm{OH}$ stretching band observed at $3345 \mathrm{~cm}^{-1}$ is particularly meaningful to discriminate the correct conformer, since it is only attributable to the cooperative $\mathrm{O}-\mathrm{H} \cdots \mathrm{O}-\mathrm{H}$ interactions occurring in the structure proposed by Chatterjee. In this crystalline structure, the primary hydroxyl group acts as hydrogen bond donor and the secondary hydroxyl group acts as acceptor. This layout maximizes the intermolecular interactions. Halogen bonding is not observed in the crystalline phase $\left(\mathrm{d}_{\mathrm{Cl}-\pi} \sim 4.4 \AA\right)$. 
The solution environment favors the conformations of higher dipole moment. Hence, the hydroxyl groups are reversed relative to the crystalline phase, and the geometries in which the dichloroacetyl group adopts the anti conformation $\left(\phi_{5}\right)$ are also stabilized. These changes allow the molecule to fold back further to form an intramolecular $\mathrm{C}-\mathrm{Cl} \cdots \pi$ halogen bond, resulting in two different conformers depending on the Chlorine atom participating in the halogen bond. In media of low dielectric constant (vacuum or solvents of low polarity), the $\phi_{5}$ dihedral $(\mathrm{HCCO})$ prefers the syn conformation, and conformer $\mathbf{I}$ is the only dominant conformer. Solvents of increased polarity increasingly stabilize conformer II over conformer I, up to the point of turning the II geometry slightly prevalent in polar solvents such as acetonitrile. In conformer II the $\phi_{5}$ dihedral (HCCO) adopts the anti conformation (resulting in a larger dipole moment) and the halogen bond is established by the second chlorine atom. In media of intermediate polarity (such as molten CHL) conformer I is expected to prevail, accompanied by a significant amount of conformer II. The two conformers can be easily distinguished experimentally by means of infrared spectroscopy taking advantage of the conformational sensitivity of the $\mathrm{C}=\mathrm{O}$ stretching band (the syn rotamer or Con $\mathbf{I}$ absorbs at lower wavenumbers).

As a final caveat, the conformations obtained in this paper using CSM models should be a good approach to the actual geometries adopted by the CHL molecules when the medium is not able to stablish strong specific interactions with the solute. In solvents stablishing strong specific interactions, the geometries obtained represent the conformation expected for the fraction of free CHL molecules (free means here not participating in specific interactions with the solute). The establishment of specific interactions with the surrounding molecules is expected to distort the geometry of the free molecules resulting in an ensemble of different interacting geometries [79], which differ from the equilibrium geometries found here particularly in the dihedrals of the groups involved in the specific interactions (recall the broad envelope observed in Fig. 3 for the $\mathrm{OH}$ stretching band of molten CHL). The detailed analysis of these structures is a complex task that is beyond the scope of this paper. 


\section{Acknowledgements}

The authors are thankful for funds from the Spanish Ministry of Innovation and Competitiveness MINECO (MAT2016-78527-P), the Basque Government, Department of Education (IT-927-16) and the EU iPROMEDAI COST Action TD1305. 


\section{References}

[1] F. E. Hahn and P. Gund, "A Structural Model of the Chloramphenicol Receptor Site," in Drug Receptor Interactions in Antimicrobial Chemotherapy. Topics in Infectious Diseases, J. Drews and E. Hahn, Eds., Vienna, Springer, 1975, pp. 245265.

[2] O. Pongs, "Chloramphenicol," in Mechanism of Action of Antibacterial Agents, F. E. Hahn, Ed., Berlin, Springer, 1979, pp. 26-42.

[3] G. P. Dinos, C. M. Athanassopoulos, D. A. Missiri, P. C. Giannopoulou, I. A. Vlachogiannis, G. E. Papadopoulos, D. Papaioannou and D. M. Kalpaxis, "Chloramphenicol Derivatives as Antibacterial and Anticancer Agents: Historic Problems and Current Solutions," Antibiotics, vol. 5, 2016.

[4] S. Kalita, B. Devi, R. Kandimalla, K. K. Sharma, A. Sharma, K. Kalita, A. C. Kataki and J. Kotoky, "Chloramphenicol encapsulated in poly-e-caprolactonepluronic composite: nanoparticles for treatment of MRSA-infected burn wounds," Int. J. Nanomedicine, vol. 10, pp. 2971-2984, 2015.

[5] World Health Organization (WHO), "Essential medicines," 04 2015. [Online]. Available: http://www.who.int/emlib/.

[6] T. R. Tritton, "Ribosome-chloramphenicol interactions: A Nuclear magnetic resonance study," Arch. Biochem. Biophys., vol. 197, pp. 10-17, 1979.

[7] M. C. Nicklaus, S. Wang, J. S. Driscoll and G. W. A. Milne, "Conformational Changes of Small Molecules Binding to Proteins," Bioorg. Med. Chem., vol. 3, pp. 411-428, 1995.

[8] M. Vieth, J. D. Hirst and C. L. Brooks III, "Do active site conformations of small ligands correspond to low free-energy solution structures?," J. Comput. Aided Mol. Des., vol. 12, pp. 563-572, 1998.

[9] J. D. Dunitz, "The Crystal Structure of Chloramphenicol and Bromamphenicol," J. Am. Chem. Soc., vol. 74, p. 995-999, 1952.

[10] C. Chatterjee, J. K. Dattagupta, N. N. Saha, W. Saenger and K. Müller, "Crystal and molecular structure of chloramphenicol," J. Cryst. Mol. Struct., vol. 9, p. 295304, 1979.

[11] K. R. Acharya, D. S. S. Gowda and M. Post, "The Structure of Chloramphenicol," Acta Cryst. B, vol. B35, pp. 1360-1363, 1979.

[12] O. Jardetzky, "Studies on the Mechanism of Action of Chloramphenicol. I. The Conformation of Chloramphenicol in Solution," J. Biol. Chem., vol. 238, pp. 2498-2508, 1963.

[13] L. A. Mitscher, F. Kautz and J. Lapidus, "Optical rotatory dispersion and circular dichroism of of diastereoisomers. I. The ephedrines and chloramphenicols," Can. J. Chem., vol. 47, pp. 1957-1963, 1969.

[14] T. M. Bustard, R. S. Egan and T. J. Perun, "Conformational studies on chloramphenicol and related molecules," Tetrahedron, vol. 29, no. 14, pp. 19611967, 1973.

[15] H. Höltje and L. B. Kier, "A theoretical Approach to Structure-Activity Relationships of Chloramphenicol and Congeners," J. Med. Chem., vol. 17, no. 8, pp. 814-819, 1974. 
[16] A. L. Fitzhugh, "Chloramphenicol: High dilution FT-IR evidence for an intramolecular hydrogen bond," Bioorg. Med. Chem. Lett., vol. 1, no. 5, pp. 257$262,1991$.

[17] D. Sajan, G. D. Sockalingum, M. Manfait, I. Hubert Joe and V. S. Jayakumar, "NIR-FT Raman, FT-IR and surface-enhanced Raman scattering spectra, with theoretical simulations on chloramphenicol," J. Raman Spectrosc., vol. 39, p. 1772-1783, 2008.

[18] S. L. Hinchley, H. E. Robertson, L. J. McLachlan, C. A. Morrison, D. W. H. Rankin, S. J. Simpson and E. W. Thomas, "Conformational Analysis with Both Experimental and Computational Data for Both Gaseous and Crystalline Phases: Unexpected Interactions in N-Methyldichloroacetamide," J. Phys. Chem. A, vol. 108, pp. 185-193, 2004.

[19] A. I. Ramos, T. M. Braga, P. Silva, J. A. Fernandes, P. Ribeiro-Claro, M. F. Silva Lopes, F. A. Almeida Paz and S. S. Braga, "Chloramphenicol-cyclodextrin inclusion compounds: co-dissolution and mechanochemical preparations and antibacterial action," CrystEng Comm, vol. 15, pp. 2822-2834, 2013.

[20] G. R. Desiraju and T. Steiner, The Weak Hydrogen Bond: In Structural Chemistry and Biology, New York: Oxford University Press, 1999, pp. 217-219.

[21] J. L. Hansen, P. B. Moore and T. A. Steitz, "Structures of Five Antibiotics Bound at the Peptidyl Transferase Center of the Large Ribosomal Subunit," J. Mol. Biol., vol. 330, pp. 1061-1075, 2003.

[22] H. D. Höltje and M. Tintelnot, "Theoretical Investigations on Interactions Between Pharmacon Molecules and Receptor Models V: Construction of a Model for the Ribosomal Binding Site of Chloramphenicol," Quant. Struct.-Act. Relat., vol. 3, pp. 6-9, 1984.

[23] L. Onsager, "Electric Moments of Molecules in Liquids," J. Am. Chem. Soc., vol. 58, no. 8, p. 1486-1493, 1936.

[24] M. W. Wong, M. J. Frisch and K. B. Wiberg, "Solvent effects. 1. The mediation of electrostatic effects by solvents," J. Am. Chem. Soc., vol. 113, pp. 4776-4782, 1991.

[25] A. V. Marenich, C. J. Cramer and D. G. Truhlar, "Universal Solvation Model Based on Solute Electron Density and on a Continuum Model of the Solvent Defined by the Bulk Dielectric Constant and Atomic Surface Tensions," J. Phys. Chem. B, vol. 113, pp. 6378-6396, 2009.

[26] A. Pung and I. Leito, "Predicting Relative Stability of Conformers in Solution with COSMO-RS," J. Phys. Chem. A, vol. 121, pp. 6823-6829, 2017.

[27] J. Zhang, H. Zhang, T. Wu, Q. Wang and D. van der Spoel, "Comparison of Implicit and Explicit Solvent Models for the Calculation of Solvation Free Energy in Organic Solvents," J. Chem. Theory Comput., vol. 13, pp. 1034-1043, 2017.

[28] K. H. Norris and P. C. Williams, "Optimization of Mathematical Treatments of Raw Near-Infrared Signal in the Measurement of Protein in Hard Red Spring Wheat. I. Influence of Particle Size," Cereal Chem., vol. 61, no. 2, p. 158-165, 1984.

[29] M. J. Turner, J. J. McKinnon, S. K. Wolff, D. J. Grimwood, P. R. Spackman, D. Jayatilaka and M. A. Spackman, "CrystalExplorer17," University of Western Australia, 2017. [Online]. Available: http://hirshfeldsurface.net. 
[30] M. J. Turner, S. Grabowsky, D. Jayatilaka and M. A. Spackman, "Accurate and Efficient Model Energies for Exploring Intermolecular Interactions in Molecular Crystals," J. Phys. Chem. Lett., vol. 5, pp. 4249-4255, 2014.

[31] C. F. Mackenzie, P. R. Spackman, D. Jayatilaka and M. A. Spackman, "CrystalExplorer model energies and energy frameworks: extension to metal coordination compounds, organic salts, solvates and open-shell systems," IUCrJ, vol. 4, pp. 575-587, 2017.

[32] S. P. Thomas, P. R. Spackman, D. Jayatilaka and M. A. Spackman, "Accurate Lattice Energies for Molecular Crystals from Experimental Crystal Structures," J. Chem. Theory Comput., vol. 14, pp. 1614-1623, 2018.

[33] A. A. Granovsky, "Firefly version 8," [Online]. Available: www http://classic.chem.msu.su/gran/firefly/index.html.

[34] M. W. Schmidt, K. K. Baldridge, J. A. Boatz, S. T. Elbert, M. S. Gordon, J. H. Jensen, S. Koseki, N. Matsunaga, K. A. Nguyen, S. Su, T. L. Windus, M. M.Dupuis and J. A. Montgomery, "General Atomic and Molecular Electronic Structure System," J. Comput. Chem., vol. 14, pp. 1347-1363, 1993.

[35] A. D. Becke, "Density-functional thermochemistry. III. The role of exact exchange," J. Chem. Phys., vol. 98, pp. 5648-5652, 1993.

[36] C. Lee, W. Yang and R. G. Parr, "Development of the Colle-Salvetti correlationenergy formula into a functional of the electron density," Phys. Rev. B, vol. 37, pp. 785-789, 1988.

[37] G. S., J. Antony, S. Ehrlich and H. Krieg, "A consistent and accurate ab initio parametrization of density functional dispersion correction (DFT-D) for the 94 elements H-Pu," J. Chem. Phys., vol. 132, p. 154104, 2010.

[38] T. H. Dunning and P. J. Hay, "Gaussian Basis Sets for Molecular Calculations," in Methods of Electronic Structure Theory, H. F. Schaefer, Ed., New York, Springer, 1977, pp. 1-27.

[39] T. H. Dunning, "Gaussian basis sets for use in correlated molecular calculations. I. The atoms boron through neon and hydrogen," J. Chem. Phys., vol. 90, no. 2, pp. 1007-1023, 1989.

[40] D. E. Woon and T. H. Dunning, "Gaussian basis sets for use in correlated molecular calculations. III. The atoms aluminum through argon," J. Chem. Phys, vol. 98, no. 2, pp. 1358-1371, 1993.

[41] F. Weigend and R. Ahlrichs, "Balanced basis sets of split valence, triple zeta valence and quadruple zeta valence quality for $\mathrm{H}$ to $\mathrm{Rn}$ : Design and assessment of accuracy," Phys. Chem. Chem. Phys., vol. 7, no. 18, pp. 3297-3305, 2005.

[42] J. G. Kirkwood, "Theory of Solutions of Molecules Containing Widely Separated Charges with Special Application to Zwitterions," J. Chem. Phys., vol. 2, pp. 351$361,1934$.

[43] M. W. Schmidt, T. L. Windus and M. S. Gordon, "Structural Trends in Silicon Atranes," J. Am. Chem. Soc., vol. 117, no. 28, p. 7480-7486, 1995.

[44] M. Maus, W. Rettig, D. Bonafoux and R. Lapouyade, "Photoinduced Intramolecular Charge Transfer in a Series of Differently Twisted Donor-Acceptor Biphenyls As Revealed by Fluorescence," J. Phys. Chem. A, vol. 103, pp. 33883401, 1999.

[45] M. M. Knopp, L. Tajber, Y. Tian, N. E. Olesen, D. S. Jones, A. Kozyra, K. Löbmann, K. Paluch, C. M. Brennan, R. Holm, A. M. Healy, G. P. Andrews and 
T. Rades, "Comparative Study of Different Methods for the Prediction of Drug-Polymer Solubility," Mol. Pharm., vol. 12, p. 3408-3419, 2015.

[46] F. Neese, "Software update: the ORCA program system, version 4.0," WIREs Comput. Mol. Sci., vol. 8, p. e1327, 2018.

[47] G. Socrates, Infrared and Raman Characteristic Group Frequencies: Tables and Charts, 3 ed., Chichester: John Wiley and Sons, 2001.

[48] R. M. Silverstein, F. X. Webster and D. J. Kiemle, Spectrometric Identification of Organic Compounds, 7 ed., Wiley, 2005.

[49] A. Hall and J. L. Wood, "Fermi resonance in hydrogen bonding," Spectrochim. Acta A, vol. 23, pp. 1257-1266, 1967.

[50] D. F. Li, Z. Hua, C. Z. Liu, C. Fan, C. L. Sun, Z. W. Li and W. J. Chen, "A study on the Fermi resonance of phenol under the effects of pressure and temperature by Raman spectroscopy," Spectrochim. Acta A, vol. 136, pp. 1767-1774, 2015.

[51] K. Ohno, T. Shimoaka, N. Akai and Y. Katsumoto, "Relationship between the Broad OH Stretching Band of Methanol and Hydrogen-Bonding Patterns in the Liquid Phase," J. Phys. Chem. A, vol. 112, p. 7342-7348, 2008.

[52] R. Iwamoto, T. Matsuda and H. Kusanagi, "Contrast effect of hydrogen bonding on the acceptor and donor $\mathrm{OH}$ groups of intramolecularly hydrogen-bonded $\mathrm{OH}$ pairs in diols," Spectrochim. Acta Part A, vol. 62, p. 97-104, 2005.

[53] J. R. Lane, J. Contreras-García, J. Piquemal, B. J. Miller and H. G. Kjaergaard, "Are Bond Critical Points Really Critical for Hydrogen Bonding?," J. Chem. Theory Comput., vol. 9, pp. 3263-3266, 2013.

[54] J. Seehusen, D. Schwarzer, J. Lindner and P. Vöhringer, "Equilibrium and midinfrared driven vibrational dynamics of artificial hydrogen-bonded networks," Phys. Chem. Chem. Phys., vol. 11, p. 8484-8495, 2009.

[55] K. Kwac and E. Geva, "A Mixed Quantum-Classical Molecular Dynamics Study of anti-Tetrol and syn-Tetrol Dissolved in Liquid Chloroform: Hydrogen-Bond Structure and Its Signature on the Infrared Absorption Spectrum," J. Phys. Chem. $B$, vol. 117, pp. 16493-16505, 2013.

[56] A. Lejardi, E. Meaurio, J. Fernández and J. R. Sarasua, "Miscibility of Poly(vinyl alcohol)-graft-Hydroxy Ester/Poly(vinylpyrrolidone) Blends," Macromolecules, vol. 44, pp. 7351-7363, 2011.

[57] H. E. Assendert and A. H. Windle, "Crystallinity in poly(vinyl alcohol). 1. An Xray diffraction study of atactic PVOH," Polymer, vol. 39, pp. 4295-4302, 1998.

[58] M. F. Santos, C. B. Braga, T. C. Rozada, E. A. Basso and B. C. Fiorin, "Rotational isomerism of some chloroacetamides: Theoretical and experimental studies through calculations, infrared and NMR," Spectrochim. Acta A Mol. Biomol. Spectrosc., vol. 129, p. 148-156, 2014.

[59] S. A. Guerrero, J. R. T. Barros, B. Wladislaw, R. Rittner and P. R. Olivato, "Conformational studies of a-substituted carbonyl compounds. Part 1.

Conformation and electronic interaction in hetero-substituted acetones by infrared and ultraviolet spectroscopy," J. Chem. Soc. Perkin Trans. 2, pp. 1053-1058, 1983.

[60] P. R. Olivato and R. Rittner, "Conformational and electronic interaction studies of some a-mono-heterosubstituted carbonyl compounds," Rev. Heteroat. Chem., vol. 15, pp. 115-159, 1996. 
[61] R. Sahnoun, Y. Fujimura, K. Kabuto, Y. Takeuchi and R. Noyori, "Hyperconjugative electron-delocalization mechanism controlling the conformational preference of fluoroacetaldehyde and methyl fluoroacetate," Bull. Chem. Soc. Jpn., vol. 79, no. 4, pp. 555-560, 2006.

[62] B. C. Fiorin, E. A. Basso, C. F. Tormena, R. Rittner and R. J. Abraham, "Theoretical and Experimental Investigation on the Rotational Isomerism in aFluoroacetophenones," J. Phys. Chem. A, vol. 113, pp. 2009-2913, 2009.

[63] R. A. Nyquist, Interpreting Infrared, Raman, and Nuclear Magnetic Resonance Spectra, Academic Press, 2001.

[64] Ö. Farkas, S. J. Salpietro, P. Császár and I. G. Csizmadia, "Conformations of ethylbenzene (CH3--CH2-Ph). An ab initio study," J. Mol. Structure (Theochem), vol. 367, pp. 25-31, 1996.

[65] G. Cinacchi and G. Prampolini, "DFT Study of the Torsional Potential in Ethylbenzene and Ethoxybenzene: The Smallest Prototypes of Alkyl- and AlkoxyAryl Mesogens," J. Phys. Chem. A, vol. 107, pp. 5228-5232, 2003.

[66] G. Zapata-Torres, B. K. Cassels, J. Parra-Mouchet, Y. P. Mascarenhas, J. Ellena and A. S. De Araujo, "Quantum-chemical, NMR and X-ray diffraction studies on (士)-1-[3,4-(methylenedioxy)phenyl]-2-methylaminopropane," J. Mol. Graph. Model., vol. 26, p. 1296-1305, 2008.

[67] A. Makriyannis and J. Knittel, "Conformational studies on phenethylamine hallucinogens: The Role of Alpha Alkyl Substitution," in NIDA Research Monograph 22: QuaSAR. Quantitative Structure Activity Relationships of Analgesics, Narcotic Antagonists, and Hallucinogens, G. Barnett, M. Trsic and R. E. Willette, Eds., New York, 1978, p. 464-478.

[68] E. Engelage, N. Schulz, F. Heinen, S. M. Huber, D. G. Truhlar and C. J. Cramer, "Refined SMD Parameters for Bromine and Iodine Accurately Model HalogenBonding Interactions in Solution," Chem. Eur. J., vol. 24, pp. 15983-15987, 2018.

[69] E. A. Del Vigo, C. Marino y C. A. Stortz, «Exhaustive rotamer search of the 4C1 conformation of $\alpha$ - and $\beta$-d-galactopyranose,» Carbohydr. Res., vol. 448, pp. 136147, 2017.

[70] A. Klamt, B. Mennucci, J. Tomasi, V. Barone, C. Curutchet, M. Orozco and F. J. Luque, "On the performance of continuum solvation methods. A comment on "Universal approaches to solvation modeling"," Acc. Chem. Res., vol. 42, pp. 489492, 2009.

[71] J. Ho, A. Klamt and M. L. Coote, "Comment on the Correct Use of Continuum Solvent Models," J. Phys. Chem. A, vol. 114, pp. 13442-13444, 2010.

[72] K. V. Ramiah and V. V. Chalapathi, "Infrared spectroscopic studies of amides and anilides," Proc. Indian Acad. Sci., vol. 58, no. 4, p. 233-243, 1963.

[73] S. Jiang, L. Zhang, D. Cui, Z. Yao, B. Gao, J. Lin and D. Wei, "The Important Role of Halogen Bond in Substrate Selectivity of Enzymatic Catalysis," Sci. Rep., vol. 6, p. 34750, 2016.

[74] M. P. Johansson and M. Swart, "Intramolecular halogen-halogen bonds?," Phys. Chem. Chem. Phys., vol. 15, pp. 11543--11553, 2013.

[75] G. Cavallo, P. Metrangolo, R. Milani, T. Pilati, A. Priimagi, G. Resnati and G. Terraneo, "The Halogen Bond," Chem. Rev., vol. 116, p. 2478-2601, 2016.

[76] S. J. Grabowski, "Non-covalent interactions - QTAIM and NBO analysis," J. Mol. Model., vol. 19, pp. 4713-4721, 2013. 
[77] C. Reichardt and T. Welton, Solvents and Solvent Effects in Organic Chemistry, Weinheim: Wiley, 2011.

[78] F. Jensen, Introduction to Computational Chemistry, 2 ed., Chichester: Wiley, 2007.

[79] M. Kolar, J. Fanfrlik, M. Lepsik, F. Forti, F. J. Luque and P. Hobza, "Assessing the Accuracy and Performance of Implicit Solvent Models for Drug Molecules: Conformational Ensemble Approaches," J. Phys. Chem. B, vol. 117, pp. 59505962, 2013. 